\title{
Pre-surgery physiotherapy and pain thresholds in patients with degenerative lumbar spine disorders
}

\author{
Yvonne Lindbäck
}

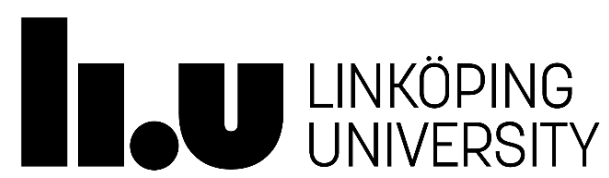

\author{
Division of Physiotherapy \\ Department of Medical and Health Sciences \\ Linköping University, Sweden
}

Linköping 2018 
Pre-surgery physiotherapy and pain thresholds in patients with degenerative lumbar spine disorders

(c)Yvonne Lindbäck, 2018

Published articles have been reprinted with the permission of the copyright holders.

Printed in Sweden by LiU-Tryck, Linköping, Sweden, 2018

ISBN 978-91-7685-276-7

ISSN 0345-0082 
To my family

"That (exercise) was what got me going. Yes, both physically and mentally that you feel that you are strengthened by it, that you don't sink deeper (into unhappiness) because you have pain, it, it is hard, sort of, to get yourself out of it maybe...."

Study participants 



\section{CONTENTS}

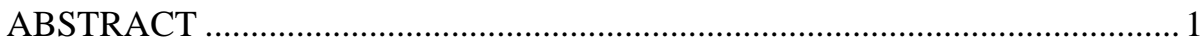

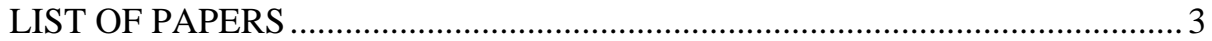

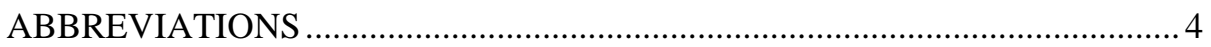

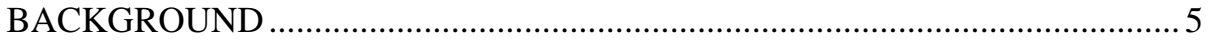

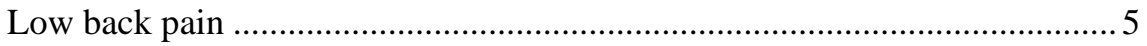

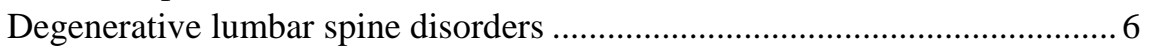

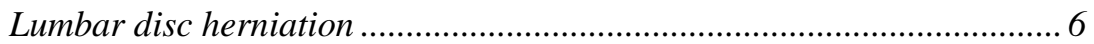

Lumbar spinal stenosis ....................................................................... 6

Psychological factors .......................................................................... 7

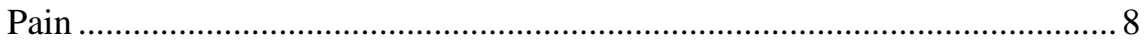

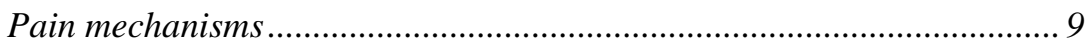

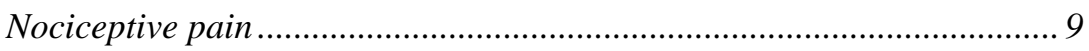

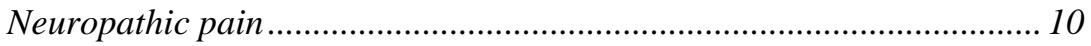

Centrally mediated pain ................................................................... 10

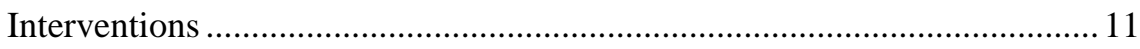

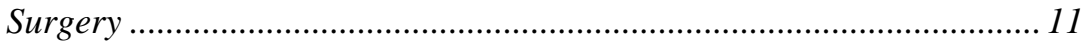

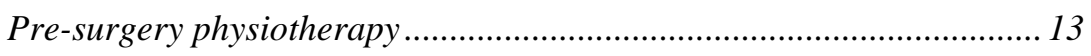

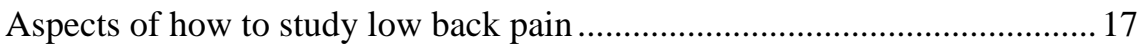

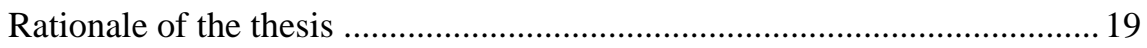

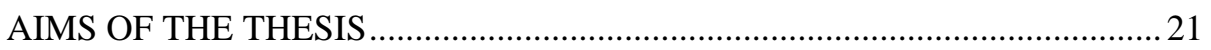

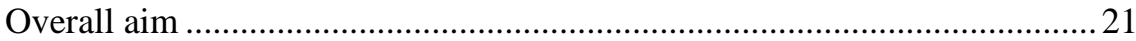

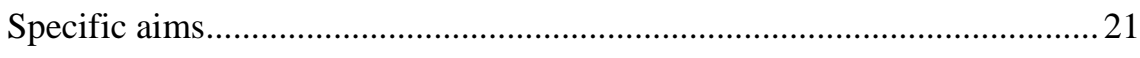

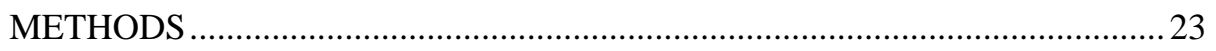

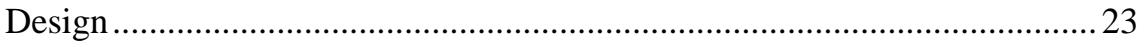

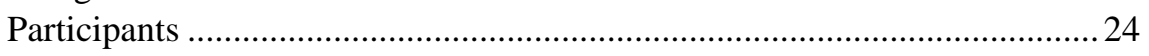

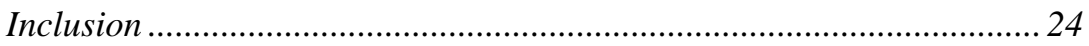

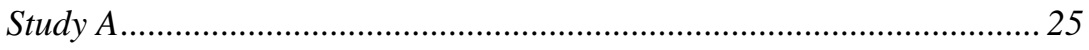

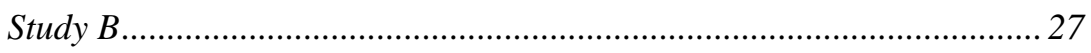

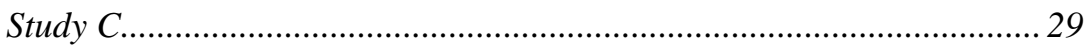




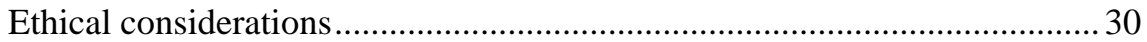

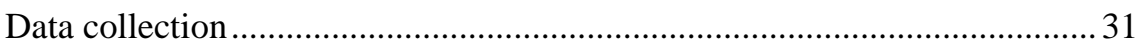

Quantitative Sensory Testing............................................................... 32

Patient-reported outcome measures....................................................... 34

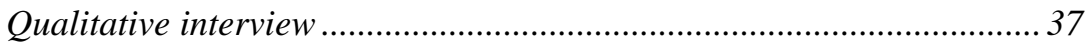

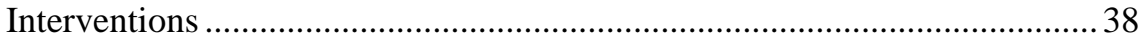

Pre-surgery physiotherapy and waiting-list interventions....................... 38

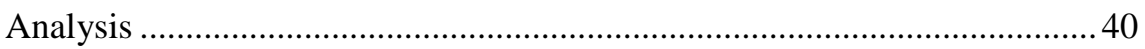

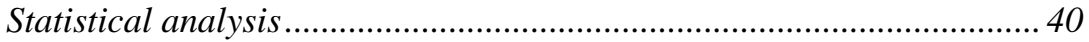

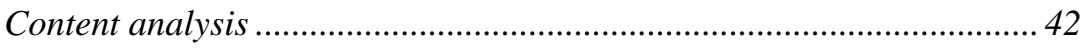

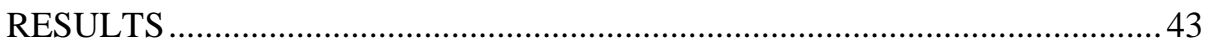

Somatosensory function measured by Quantitative sensory testing ..............43

Somatosensory profile of patients on a group level compared to

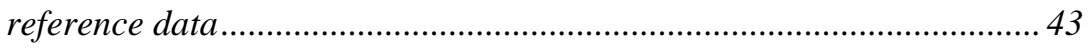

Altered somatosensory profile .................................................................. 43

Patient-reported outcome measures in patients with or without an altered somatosensory profile ………………………............................ 43

Associations between pain sensitivity in hand and patient-reported outcome measures before, 3 months and 1 year post-surgery in patients with lumbar disc herniation or spinal stenosis ........................................ 44

Pre-surgery physiotherapy - patient-reported outcome measures ................. 46

Between-group and within-group comparisons ...................................... 46

Pre-surgery physiotherapy - patients' experiences ........................................... 49

Patients' experiences of how symptoms are explained and their experiences of the influences on back-related health after pre-surgery

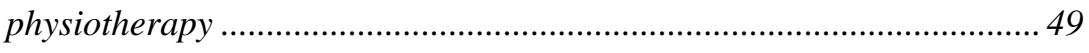

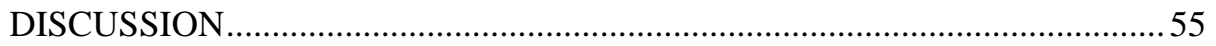

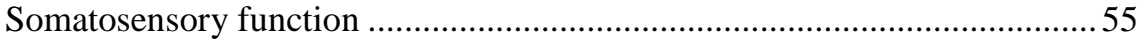

Pre-surgery physiotherapy - patient-reported outcome measures .................55

Pre-surgery physiotherapy - patients' experiences ……………………….....55

Experiences of how symptoms are explained ............................................. 59

Patients' experiences of the influences on back-related health after pre-

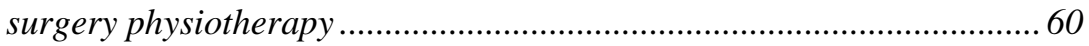

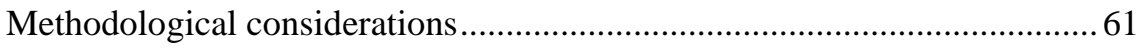




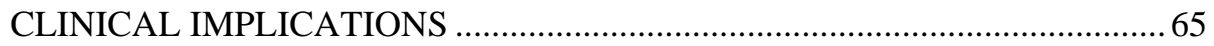

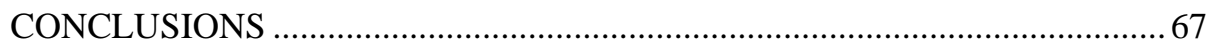

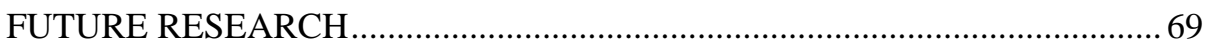

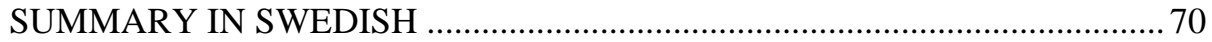

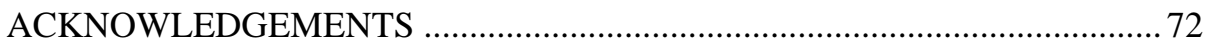

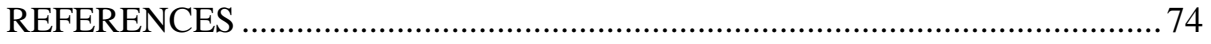





\section{ABSTRACT}

Background: Patients scheduled for spinal surgery often experience long duration of pain, which may influence the pain-regulation system, function and health and have an impact on post-surgery outcome. Prehabilitation potentially augments functional capacity before surgery, which may have beneficial effects after surgery.

Aim: The overall aim of the thesis is to study pre-surgery physiotherapy and somatosensory function in patients with degenerative lumbar spine disorders and to explore the patients' experiences of pre-surgery physiotherapy.

Methods: Somatosensory function was measured with quantitative sensory testing (QST). Pre-surgery physiotherapy was evaluated with patient-reported outcome measures $(n=197)$. Patients' experiences of how symptoms are explained and their experiences of the influences on back-related health after pre-surgery physiotherapy were explored.

Results: Half of the patients reported back or leg pain for more than 2 years. On a group level, the somatosensory profiles were within the reference range. On an individual level, an altered somatosensory profile was found in 23/105 patients, these were older, more often women, and reported higher pain, larger pain distribution and worse SF-36 MCS (mental health component summary).

Patients with disc herniation, more sensitive to pressure pain in the hand presurgery, was associated with poorer function, self-efficacy, anxiety and depression score pre-surgery, worse function, self-efficacy and leg pain 3 months post-surgery and worse health related quality of life, self-efficacy, depression score 1 year postsurgery. The results for sensitivity for cold pain were similar, except that it even was associated with poorer function and pain 1 year post-surgery.

The pre-surgery physiotherapy group had less back pain, better function, health, self-efficacy, fear avoidance score, depression score and physical activity level than the waiting-list group after the pre-surgery intervention. The effects were small. Both groups improved significantly after surgery, with no differences between groups, except that the higher physical activity level in the physiotherapy group remained at the 1-year follow-up. Only 58\% of the patients reported a minimum of one visit for rehabilitation during the 1 year preceding the decision to undergo surgery.

Patients experienced that pre-surgery physiotherapy had influenced symptoms, physical function, coping, well-being and social functioning to various degrees. Pre-surgery physiotherapy was experienced as a tool for reassurance and an 
opportunity to reflect about treatment and lifestyle. The patients mainly used biomedical explanatory models based on image reports to explain their backrelated symptoms. Both broader and more narrow, as well as lack of explanations of symptoms emerged. Further, wanting and sometimes struggling to be wellinformed about symptoms and interventions were described.

Conclusions: Being more sensitive to pressure- and cold pain in the hand, as a sign of widespread pain pre-surgery, was associated with poorer function, pain and health at post-surgery in patients with disc herniation.

Pre-surgery physiotherapy decreased pain, fear avoidance, improved health related quality of life; and it decreased the risk of a worsening in psychological well-being before surgery. The improvements were small, and improvements after surgery were similar for both groups. At the 1-year follow-up, the physiotherapy group still had a higher activity level than the waiting list group. The pre-surgery physiotherapy was well tolerated. Patients' reported experiences also illustrates the influence on function, pain and health. Patients experienced that pre-surgery physiotherapy provided reassurance and gave time to reflect on treatments and lifestyle. Symptoms were mainly described in line with a biomedical explanatory model. Those using a broader explanation were confident that physiotherapy and self-management could influence their back-related symptoms. 


\section{LIST OF PAPERS}

I. Lindbäck Y, Tropp H, Enthoven P, Gerdle B, Abbott A, Öberg B.

Altered somatosensory profile according to quantitative sensory testing in patients with degenerative lumbar spine disorders scheduled for surgery. BMC musculoskeletal disorders. 2017;18(1):264.

https://doi.org/10.1186/s12891-017-1581-6

II. Lindbäck Y, Tropp H, Enthoven P, Gerdle B, Abbott A, Öberg B.

Association between pain sensitivity in the hand and outcomes after surgery in patients with lumbar disc herniation or spinal stenosis.

European Spine Journal. 2017:1-8.

https://doi.org/10.1007/s00586-017-4979-9

III. Lindbäck Y, Tropp H, Enthoven P, Abbott A, Öberg B.

PREPARE: pre-surgery physiotherapy for patients with degenerative lumbar spine disorder: a randomized controlled trial.

The Spine Journal: official journal of the North American Spine Society. Dec 2017.

https://doi.org/10.1016/j.spinee.2017.12.009

IV. Lindbäck Y, Enthoven P, Öberg B.

Patients' experiences of how symptoms are explained and influences on back-related health after pre-surgery physiotherapy. Submitted 


\section{ABBREVIATIONS}

LBP

CLBP

LSS

LDH

DDD

MRI

PROMs

ODI

VAS

EQ-5D

SF-36 PCS and MCS

FABQ-PA

HADS

SES

PGIC

PSFS

CSI

NE

CBT

QST

CDT

WDT

CPT

HPT

PPT

TBC

SD

CI

SEM

MCIC

MDC

OCP

AUC

$\beta$
Low back pain

Chronic low back pain

Lumbar spinal stenosis

Lumbar disc herniation

Degenerative disc disease

Magnetic resonance imaging

Patient-reported outcome measures

Oswestry Disability Index

Visual Analogue Scale

European Quality of Life, EuroQuol-5D

Short Form-36 health related quality of life Physical and

Mental health Component Summary scores

Fear-Avoidance Belief Questionnaire in Physical Activity

Hospital Anxiety and Depression Scale

Self-Efficacy Scale

Patient Global Impression of Change

Patient Specific Functional Scale

Central Sensitization Inventory

Neuroscience education

Cognitive behavioural therapy

Quantitative sensory testing

Cold detection threshold

Warmth detection threshold

Cold pain threshold

Heat pain threshold

Pressure pain threshold

Treatment based classification

Standard deviation

Confidence interval

Standard error of mean

Minimally Clinical Important Change

Minimal Detectible Change

Optimal Cutoff Point

Area Under the Curve

Standardized beta 


\section{BACKGROUND}

\section{Low back pain}

Low back pain (LBP) causes most disability globally of 200 diseases and disorders that have been examined, measured in years lived with disability (1). Years lived with disability for LBP has increased by $50 \%$ since 1990, and is expected to increase as a consequence of an aging and increasing population (2). Lifetime prevalence is now as high as $84 \%$ (3) and the condition is common in all age groups and on all continents. Furthermore, the recurrence rate of LBP is high, 33\% annually, and little is known about factors that predict recurrence after a first episode of LBP (4). In up to $85 \%$ of patients, a clear aetiology cannot be identified. Instead, LBP is described as 'multifactorial' with multiple biological and behavioural aetiologies (5), requiring a biopsychosocial perspective both in the clinical care of patients with LBP and in research $(5,6)$. The biopsychosocial model was developed by Engel in 1977 (7). Its key points are to expand the use of the knowledge from the patient, to understand both multiple aetiologies and effects in the patient's context to treat the individual needs of each patient. This requires an ability to use the biopsychosocial dimensions in the model simultaneously throughout the care process (7). In the assessment of patients with LBP, the international guidelines focus on screening for serious pathology (red flags), neurological symptoms and psychosocial risk factors (yellow flags). Red flags are signs that indicate a possible underlying serious condition and need rapid further assessments (8).

In guidelines from Canada and the UK, the target population is people with LBP with or without sciatica (9-11), without identification of the causes of pain or anatomical structure involved (12). The US guidelines are similar, but include lumbar spinal stenosis (LSS), in addition to LBP and radicular pain (10). The prevalence of sciatica in the general population ranges from $10 \%$ to $25 \%$ annually (13). Sciatica causes pain of a longer duration and higher intensity, with greater disability and a lower quality of life than LBP alone causes. Sciatica requires greater healthcare usage, including more surgical interventions (14). The most common reason for sciatica in younger people is lumbar disc herniation (LDH), and in older people LSS (15). 


\section{Degenerative lumbar spine disorders}

Degenerative lumbar spine disorder is an overall term that describes about $15 \%$ of all LBP. Patients with LDH and LSS are the largest groups, while those with spondylolisthesis and degenerative disc disease (DDD), also known as segmental pain, are smaller groups of degenerative lumbar spine disorders (15). Spondylolisthesis is the forward displacement of a vertebra, most commonly L5. The displacement is graded in a four-grade scale, where grade 1 is $0-25 \%$ displacement of the vertebra (16). Symptomatic spondylolisthesis causes local back pain with or without sciatica during and after activity. Asymptomatic degenerative spondylolisthesis occurs in $23 \%$ of the population in the age range 60-70 years, and increases to $35-50 \%$ in people older than 70 (17). Isthmic spondylolisthesis occurs in adolescence and is often asymptomatic, but its presence should be considered. Its more common in younger performance sports activities, and especially at the elite level $(18,19)$.

\section{Lumbar disc herniation}

LDH with radiculopathy is defined as localized displacement of disc material beyond the normal margins of the intervertebral disc space, resulting in pain, weakness or numbness, in a myotomal or dermatomal distribution (20). LDH accounts for approximately 5\% of all LBP (21). LDH has a good prognosis, and most patients improve significantly during two to three months $(17,22)$. Large $\mathrm{LDH}$ is more common in men than in women (23), and large $\mathrm{LDH}$ resolves better than small (24). To reach a diagnosis of LDH, it is necessary that clinical presentation is consistent with the findings of magnetic resonance imaging (MRI) or computed tomography (20). Disc bulging is common and appears in $30 \%$ of people 20 years of age. It rises to $84 \%$ in people 80 years of age (17). Further, the prevalence of LDH in MRI was as high as $76 \%$ in matched asymptomatic controls in a study of patients with symptomatic LDH (25). The frequent occurrence of both asymptomatic disc bulging and LDH complicates the diagnostics.

\section{Lumbar spinal stenosis}

LSS is recognized as "a clinical syndrome of buttock or lower extremity pain, which may occur with or without back pain, associated with diminished space available for the neural and vascular elements in the lumbar spine" (26). Degeneration of the intervertebral disc results in a loss of segmental height and disc bulging, which leads to hypertrophy of the facet joints and thickening of the ligamentum flavum. The reduced dimensions of the spinal canal and compression of the neural and vascular elements cause the collection of symptoms known as 'intermittent neurogenic claudication'. 
LSS is common, with an estimated prevalence of $6 \%$ in the general population from a study in Japan (27). The prevalence of LSS increases with age and peaks at age 70-79 years. LSS occurs equally in men and women (27). The prevalence determined only on imaging findings, and the condition is defined as either 'absolute LSS' (with a spinal canal of diameter under $10 \mathrm{~mm}$ ) or 'relative LSS' (with a spinal canal of diameter greater than $12 \mathrm{~mm}$ ), the prevalences in those aged $60-69$ are $19 \%$ and $47 \%$, respectively (28). It is expected that the need of intervention will increase significantly as the population ages and increases (26).

When there is no gold standard for the diagnosis of LSS, better diagnostic criteria have been requested in order to decrease the costs of examinations and improve individual treatment (29). Because of that, an international Delphi study was performed which suggests that six questions posed during history taking, gives a clinical diagnosis with a certainty of $80 \%$ (30). The four most frequently used questions in the Delphi group were: "Leg or buttock pain while walking?", "Flex forward to relieve symptoms?", "Feel relief when using a shopping cart or bicycle?", "Motor or sensory disturbance while walking?" (30). A clinical presentation of the signs and symptoms of LSS must be confirmed by imaging before a diagnosis of LSS can be made. The high prevalence of degenerative changes, especially in older patients, makes it difficult to decide whether the imaging findings are the cause of pain and symptoms or not (26). The fact that $21 \%$ of LSS demonstrated by MRI is non-symptomatic (31) also complicates the diagnosis.

The most common symptom is unilateral or bilateral leg symptoms while walking. Symptoms are abolished by bending forward or sitting, as these movements increase the dimensions of the spinal canal and foramina. The decreased walking distance significantly influences daily life, and people with LSS report a lower quality of life than people with osteoarthritis in the knee and hip (32). In people 60 years and older, diabetes mellitus, urological disorders, and osteoarthritis/fracture have been reported as comorbidities, and depressive symptoms are associated with LSS (33). Screening for these associated factors helps to draw up a tailored intervention.

\section{Psychological factors}

Many psychosocial factors play a role in degenerative lumbar spine disorders. After surgery for LDH, continued post-surgery pain is most strongly associated with depression (34), and depression is a prognostic factor for disability after surgery for spinal stenosis (35). Other psychosocial factors associated with a poor post-surgery outcome for patients with LDH are anxiety (36), passive avoidance coping strategies $(37,38)$, fear of movement/(re)injury, and negative outcome expectations (37). In patients with LSS, low pre-surgery European Quality of Life 
(EuroQuol-5D, EQ-5D) predicts more back and leg pain 1-year post-surgery (39). Patients with LSS have lower job satisfaction and higher perceived stress than those without LSS (40). These are all important factors to include when making a decision about intervention, not only due to the risk of a poor outcome, but also to ensure that the symptoms from which the patient is suffering are targeted. Another factor is treatment expectation; in patients with non-specific LBP, those with greater positive expectation gain more benefit from non-surgical treatments (such as acupuncture, group cognitive behavioural approach, group exercise, and manual therapy followed by exercise) (41).

\section{Pain}

The International Association for the Study of Pain (42), uses the following wellknown definition of pain:

"An unpleasant sensory and emotional experience associated with actual or potential tissue damage, or described in terms of such damage”.

The definition of pain (42) describes both the biological dimension of perceiving the pain and the psychological dimension of emotions about the pain, which influence social functioning. The biological dimension may be any of three factors: activation of the nociceptive system because of a tissue damage, a warning signal to avoid tissue damage, or centrally mediated pain without detectable tissue damage. The biological and psychological perceptions of pain are the output patterns from the neuromatrix (43). This is the term used to describe the complex interactions in the pain-regulation system, including extensive areas in the central nervous system (CNS), such as the somatosensory area, limbic system, thalamus and cortex. The neuromatrix is dynamic and constantly produces output patterns, the perception of the body. The input information to the neuromatrix comes from not only the sensory system but also from cognitive-related brain areas (memories of earlier experiences, thoughts and anxiety), and from emotion-related brain areas such as the stress-regulation system and the limbic system $(43,44)$. The amygdala, in particular, plays an important role for negative emotions and pain-related memories, referred to as the fear-memory centre (45). All input information is modified in the neuromatrix and new output patterns are produced. The output includes not only the perception of pain (sensory, affective and cognitive dimensions), but also voluntary and involuntary action programmes and stressregulation programmes (Figure 1) $(43,44)$.

The complexity of the pain system means that broad assessments that cover all possible aspects that can influence the symptomatology in LBP are required. It 
is generally recommended that the scope of the clinical reasoning process be widened from a purely biomedical one to one that includes psychosocial dimensions (8).

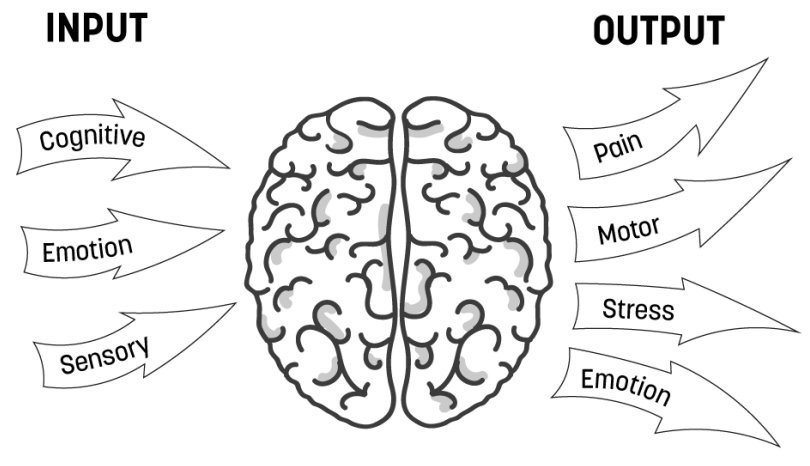

\section{NEUROMATRIX}

Figure 1 Neuromatrix describs the complex intraction in the pain-regulation system. The input information comes from the sensory system and also from emotional and cognitive brain areas. From the input information, new output pattern, our biological and psychological perception of pain, are constantly produced (43). Picture illustrated by Emma Busk Winquist.

\section{Pain mechanisms}

In degenerative lumbar spine disorders, nociceptive pain from non-neural lumbar structures and neuropathic pain from nerve compression are expected. It is, however, possible that the pain arises from both peripheral processes (as is the case for nociceptive, inflammatory and neuropathic pain), and from centrally mediated pain mechanisms (46). This is particularly a risk, when most patients scheduled for spinal surgery, have more than three months duration (15). Three month' pain duration is defined as 'persistent pain', and it is expected that most of the acute healing process has passed (42). It has been suggested that the risk that the pain state becomes centrally mediated pain increases after approximately three months.

\section{Nociceptive pain}

Nociceptive pain occurs as a consequence of the activation of free nerve endings, the peripheral terminals of the nociceptors. The nociceptors have a high threshold, and are one type of primary sensory neuron (47). Typically, the activation is due to mechanical stimuli, but can also be due to thermal or chemical stimuli $(47,48)$. The stimuli activate the nociceptor by changing the membrane-bound transduction, which causes action potentials to propagate (48). The action potential is conducted from the peripheral terminal along either thinly myelinated A delta axons, or unmyelinated $\mathrm{C}$ fibre axons to the dorsal root ganglion. The signal then passes to 
the tractus spinothalamicus in the spinal cord to the brain stem, thalamus, and onwards to the somatosensory cortex. Transmission is the synaptic transfer and modulation of input between neurons, where the first transmission is from primary to secondary neurons in the dorsal root ganglion. Perception requires the discrimination of the location in the somatosensory cortex and cognition in the prefrontal cortex (47). Evidence of tissue damage in the area in which pain is experienced is needed to confirm that a nociceptive pain state exists. Further criteria may be obtained from image report and mechanical pathology or normal movement causing increased pain are also signs of nociceptive pain (48).

\section{Neuropathic pain}

Neuropathic pain is caused by a lesion or disease of the somatosensory nervous system (42). The radiculopathy experienced in LDH is caused both by mechanical compression of the nerve and by a chemical process that arises due to the extruded disc material. Thus, the pain in LDH is from both a neuropathic state and an inflammatory state $(48,49)$. Evidence of a sensory nerve lesion, such as LDH or LSS, must be available from image report to confirm a neuropathic pain state from the lumbar spine. Further criteria for neuropathic pain state are; the typical symptoms with sensations of burning, tingling, paresthesias or dysesthesias, and there may be clinical signs from a nerve tension test, decreased pinprick sensitivity, increased vibration sense, or mechanical and cold allodynia (48).

\section{Centrally mediated pain}

A pain state in which nociceptive, inflammatory and neuropathic pain states can be ruled out is referred to as 'centrally mediated pain' or 'dysfunctional pain'. Further criteria are increased excitation and reduced inhibition (48). A centrally mediated pain is mainly seen as a secondary pain state, where a previous pain mechanism has been alleviated (48), but can also be present together with nociceptive and or neuropathic pain state (46).

The pain states described above are all relevant in patients with degenerative lumbar spine disorders. During the assessment of a patient's symptoms in the diagnostic process, it is recommended that the pain mechanisms involved are analysed in order to improve treatment selection $(46,48)$. The two most common reasons of persistent pain in patients at pain clinics are musculoskeletal pain and post-surgery pain (50), which means that a broad analysis of the pain mechanisms in patients with degenerative lumbar spine disorders in an early stage is important. 


\section{Interventions}

As earlier mentioned, the prognosis in LDH is in general good (17), with $73 \%$ improving significantly within 12 weeks (22). The proportion of people with LDH who undergo surgery is unclear, since many people with sciatica do not seek care, but about 10\% who still have severe pain after 6 weeks consider surgery (17).

The natural history in LSS is not well known, but a working group for LSS guidelines in the US concluded that in patients with mild to moderate LSS treated with non-surgical intervention followed for 2-10 years, 20-40\% will require surgery. Further, $50-70 \%$ of those who received a non-surgical intervention will improve in their pain (51). However, only $10 \%$ of clinical studies that have investigated the effect of surgery have included information about the use and outcome of non-surgical intervention before surgery for LSS (52). It is thus not clear in such studies whether patients have been given the opportunity to exhaust non-surgical interventions before deciding to undergo surgery.

It is recommended that non-surgical interventions be exhausted before deciding to undertake surgery for $\operatorname{LSS}(10,51), \operatorname{LDH}(9,10,20)$, spondylolisthesis $(53)$, or DDD $(9,10)$. Exercise plays a major role in the treatment of chronic LBP with or without sciatica according to three large recently updated guidelines (911), of which the UK guidelines give exercise the most central role in non-surgical interventions. All three guidelines also recommend multimodal care that includes self-management and psychological approaches (12). Information to the patient about symptoms and treatments plays a major role and patients should be involved in their care to be able to make informed decisions about their care (9).

\section{Surgery}

Surgery can be considered in LDH when non-surgical intervention has not improved pain and function and imaging reports are consistent with sciatic symptoms (9). This provided that the patient is interested in having a surgical intervention if appropriate. In LSS referral for surgical opinion can be considered if severe pain or limitation in function are still present after a physical and, if needed, psychological, intervention programme for usually six months, and if the patient is willing to consider surgery (11).

Assessment for signs of psychological distress, such as somatization and/or depression, prior to surgery is recommended (20). There is evidence level B (fair evidence) that patients with signs of psychological distress have worse outcomes, compared to those without such signs (20). Those with significant psychological distress should be referred to appropriate intervention before surgery to optimize outcome after surgery $(9,20)$. 
The effect mechanism in spinal surgery is to remove the pain generator. Different techniques may be used for surgery of LBP. For LDH, comparison between standard procedure (micro discectomy or open discectomy) and a newer procedure (minimally invasive discectomy), showed only small differences, and further studies are needed to conclude if the newer technique is an adequate alternative (54). Fusion surgery as a complement to decompression is not recommended in LSS with or without degenerative spondylolisthesis, due to lack of superior outcome $(9,55)$, higher cost, more blood loss and longer surgery time and a higher complication rate (56), up to $20 \%$ (9). In UK guidelines, fusion surgery and disc replacement are not recommended in LBP (9).

Acute surgery is indicated if serious pathology is present. This concerns mainly cauda equina symptoms and myelopathy (can be present at L1 in the lumbar spine), but there can also be other indications such as high pain intensity $(20,51)$.

Surgery leads to larger short-term benefits in reducing pain and disability in both LDH and LSS compared to non-surgical intervention (57). While for the longterm the results are similar for surgical- and non-surgical intervention in LDH (57), which is in line with earlier results for 1-year $(21,58)$ and 2-year follow-ups $(21$, 57). In LSS there are contradictory results for long-term outcome, whereas surgical- and non-surgical intervention have shown similar effects in function at 2-year follow-up (59), while another study showed superior effect for surgery at 2-year follow-up (57). At 1-year follow-up, most patients with LDH and LSS are satisfied with the surgery results, but $22 \%$ of those with $\mathrm{LDH}$ are doubtful or dissatisfied with the result and the numbers for those with central and lateral LSS are $33 \%$, and $39 \%$, respectively (15).

Recurrent $\mathrm{LDH}$ at the same level within the first year after surgery was $12 \%$ in a study of 141 participants (60). However, the recurrence rate varies, in a review recurrent $\mathrm{LDH}$ ranged from $0 \%-23 \%$ and resurgery ranged from $0 \%$ to $13 \%$ within 2 years after surgery (61). The same review also reported recurrent LBP to be $3 \%$ $34 \%$ in the same time frame (61). Comparing resurgery for recurrent LDH and first time surgery, the resurgery group had poorer results in pain and function, and a lower number of satisfied patients (62).

LSS is the most common reason for lumbar spine surgery $(15,26)$. In Sweden, LSS is the most common reason for spinal surgery, representing $52 \%$ of the patients having surgery for degenerative lumbar spine disorders registered in the Swedish spine register (15). Second most common reason is $\mathrm{LDH}(28 \%)$, followed by DDD $8 \%$, spondylolisthesis $4 \%$, and other diagnosis $8 \%$ (15). There is a large variation in performed interventions in different regions in the US and differences depending on gender, where women receive more often non-surgical treatment and men more often fusion procedures (63). 


\section{Pre-surgery physiotherapy}

'Prehabilitation' is the term used to describe augmenting functional capacity before surgery (64), and this process may have a beneficial effect on outcome after surgery (65). Pre-surgery physiotherapy is part of prehabilitation when only physiotherapy interventions are used. Few studies have evaluated prehabilitation before spinal surgery (66-69). Three studies evaluated an education intervention $(66,68,69)$, while a fourth study evaluated an intervention package including a pre and post-surgery exercise-programme together with other components (67). The interventions of these four studies are reviewed below, to summarize current knowledge about prehabilitation in spinal surgery.

\section{Pain biology education with a cognitive behavioural approach}

Louw et al. (66) evaluated a pain education intervention that included a visit to a physiotherapist and information in printed form, in patients with radiculopathy due to LDH. The mean age of the participants was 50 years, and they had experienced pain for less than 90 days. The pain education did not improve function, nor reduce back or leg pain compared to the control group, but gave long-term effects: healthcare consumption 1 year and 3 years post-surgery was lower $(66,70)$. The pain education was developed by Butler and Moseley and is well-known as "Explain Pain". It has had positive effects in patients with chronic low back pain (CLBP) (71). The aim of the intervention is to reduce the fear of LBP, by reconceptualising the patients' thoughts, feelings and actions about their pain state through knowledge of pain biology (71). Patho-anatomical models are used in traditional biomedicine pain education, but these are not used in "Explain Pain", due to the criticism that their use can increase avoidance behaviour (71, 72). "Explain Pain" has been adapted to a prehabilitation intervention for patients with radicular pain (66), and now goes under the name neuroscience education (NE). $\mathrm{NE}$ contains information about the grounds on which the decision to undergo surgery can be made, the neurophysiology, peripheral nerve sensitisation, spinal inhibition and facilitation, post-surgery recovery, and the scientific evidence that $\mathrm{NE}$ is beneficial. The opportunity is given to send written questions to the surgeon (66). NE explains that any persistent pain experienced after surgery is probably due to increased sensitivity of the nervous system, and not to persistent tissue pathology. Further, the material explains that the sensitive nervous system needs exercise to become less sensitive (66).

$\mathrm{NE}$ is an intervention based on cognitive behavioural therapy (CBT) the specific treatment mechanism of which is to change attitudes towards adopting a self-management approach to the problem (73). This specific treatment mechanism is supplemented by general treatment mechanisms that include patients' evaluation 
of quality of the working alliance, and patients' expectations of benefits. Both the specific and the general treatment mechanisms have been evaluated in CBT for chronic pain. The treatment mechanisms change significantly early in the treatment process, and are related to changes in outcomes later in the treatment process (73). The findings have led to the suggestion that greater emphasis should be placed on the treatment mechanisms to improve outcomes (73). The change in attitudes towards more self-management observed by Louw et al. (66) may be the treatment mechanism of NE that leads to a lower need for healthcare.

\section{A multidisciplinary cognitive behavioural therapy intervention}

Rolving et al. (69) evaluated a multidisciplinary CBT intervention in patients with spondylolisthesis (grade 1-2) or DDD. The intervention consisted six 3-hour group-visits, four before and two after surgery. The topics covered in the intervention were; the interaction between cognition and pain perception, coping, pacing, ergonomics, return to work and information about the surgical procedure. Values of Oswestry Disability Index (ODI) were significantly better in the intervention group $(n=59$, mean age 51 years) than in the control group $(n=31$, mean age 48 years) at the 3 -month follow-up, but the difference became smaller at 6 and 12-month follow-up. There were no differences between the groups in pain on Visual Analogue Scale (VAS), Fear Avoidance Belief Questionnaire in Physical Activity (FABQ-PA) or on Coping Strategies Questionnairecatastrophizing subscale. The results for the psychological variables were described as "surprising", since the intervention had targeted those aspects. The return to work rate was low, $42 \%$, at the 1-year follow-up, and did not differ between the groups. The results suggest that intervention for patients with spondylolisthesis (grade 1-2) or DDD needs to be improved (69).

\section{A feedback session of the pre-surgery information}

Kesanen et al. (68) evaluated a feedback session that was based on a knowledge test, after the routine pre-surgery information for patients who were to undergo surgery for LSS $(n=100)$. The feedback session aim was to support the participants' empowerment. The knowledge test about the pre-surgery information covered the following domains: bio-physiology (e.g. aetiology, symptoms, treatment, and complications), function (e.g. mobility, rehabilitation, rest, and nutrition), social aspects (patient unions, family, and work), experiential aspects (emotions, attitudes), ethics (patient rights, participation in decision-making and confidentiality), and financial considerations (costs and social benefits). The intervention group (mean age 62 years) had lower anxiety pre-surgery than the control group (mean age 63 years), but the patient-reported outcome measures 
(PROMs) values for the two groups after surgery did not differ. This led to suggestion that post-surgery rehabilitation be added, and the patient education be repeated based on patients' needs, in the attempted to improve the post-surgery outcome by decreasing anxiety (68). The effect of negative thoughts about pain was studied in an experimental visceral pain test showing that nocebo effects contribute to central pain amplification. This effect may play a role in the transition from acute to chronic pain and the maintenance of chronic symptoms (74). The results show how important it is to decrease negative thoughts before an intervention.

\section{Additional pre-surgery information in a prehabilitation and early rehabilitation programme}

Nielsen et al. (67) evaluated a prehabilitation and early rehabilitation intervention in patients with degenerative lumbar spine disorders with radiating leg pain $(\mathrm{n}=$ 73). The intervention-package included: education, exercise, protein drinks, selfmonitored analgesic use, and early post-surgery rehabilitation (67). The intervention content was chosen from interventions that had improved postsurgery outcomes in other surgery than spinal surgery (75). A review of multimodal strategies to improve surgical outcome concluded that understanding pathophysiology and the clinical reasoning for interventions reduces stress about surgery, which increases the pace of rehabilitation and increases satisfaction and safety (75). The education component comprised an additional visit to receive information about surgery, post-surgery mobilisation and rehabilitation. The intervention group (mean age 48 years) experienced less LBP after surgery, faster recovery and shorter hospital stay than the control group (mean age 52 years). More patients were "Very satisfied" with the overall treatment than in the waiting list group. The groups did not differ in any measure at the 3 or 6-month follow-up (67). The exercise programme used is described in the next paragraph.

\section{Exercise programme in a prehabilitation and early rehabilitation programme}

Nielsen et al. (67) used an individualized exercise programme of duration 30 minutes, to be performed every day for 6-8 weeks at home before surgery for the intervention group. The programme focused on an increase in the strength of trunk muscles and cardiovascular conditioning, and was supervised twice by a physiotherapist. Post-surgery the intervention group had two 30 minutes mobilisation and exercise sessions instead of one during the hospital stay. There were similar exercises pre- and post-surgery, without further description of type of exercises, number of exercises or repetitions per exercises (67). The recommendation for development and maintaining cardiorespiratory, muscular 
fitness, and flexibility in healthy adults one set of 8-12 repetitions or 10-15 repetitions for older and more frail persons, for 8-10 exercises (76). Exercise is a type of physical activity consisting of repetitive, planned and structured bodily movement to maintain or improve components of physical fitness (77).

There is a lack of studies about effects and effect mechanisms in patients with degenerative lumbar spine disorders. Exercise has many possible effects on different dimensions of the biopsychosocial model. There are both peripheral effects, in patients with LBP in the lumbar spine, and as well as central effects (46). Some effects and potential effect mechanisms are described here.

Exercise has an immediate pain decreasing effect (hypoalgesia) measured by pain intensity and pain thresholds before and after one intervention in healthy participants. This exercise-induced hypoalgesia is present in dynamic resistance exercise with a large hypoalgesic effect size and aerobic exercise and isometric exercise have moderate effect sizes (78). Aerobic exercise performed by stationary cycling in 25 minutes at $70 \%$ and $50 \%$ of heart rate respectively, both had a hypoalgesic effect (79), and larger effect in the higher intensity $(79,80)$. In participants with chronic pain the effect size for exercise-induced hypoalgesia is varying, possibly depending on type of medical condition and the intensity of the exercise (78). The findings make assessment of pain state essential (46), to optimise the intervention, as described earlier.

The effect mechanism for exercise-induced hypoalgesia is complex, unclear, and mostly studies on animals (80). One potential pain neurophysiological explanation is that exercise activate the endogenous opioids system, which reduces pain sensitivity (79). Further, the cardiovascular system is effected by exercise, whereof one potential effect mechanism is that the change in blood pressure during exercise activates the endogenous opioid system (80). The exercise influences on group III and VI muscle afferents, has been explained to increases pain thresholds. Another described effect mechanism is that exercise influences the nonopioid pain inhibitory system and endocannabinoids reduce the pain sensation (81). The feeling of well-being in long-distance running known as "runners high" might potentially depend on this effect mechanism (81).

In radicular pain, there is low quality evidence that exercise give small improvements in pain and function compared to usual care or no exercise, which was concluded in US guidelines from studies in outpatient clinics (10). In patients with LSS, being surgical candidates and randomized to either surgery or physiotherapy with exercise and information had similar effect in function, neurogenic symptom scale and treatment expectations at 10 weeks, 26 weeks, 1 and 2 years (59). There were no further analysis of possible effect mechanisms. 
There is moderate evidence that fear avoidance exercise, which emphasises that exposure is more effective than graded activity in the reduction of fear avoidance, pain and disability in patients with CLBP (72). Anxiety and memories of painful movements have negative impact on thoughts, feeling and actions in neuromatrix (44). Targeting fear avoidance, the maladaptive behaviour, improve pain and disability.

In people with mild to moderate depression, exercise has comparable effects as antidepressant medication and psychotherapy, and in severe depression, exercise is presented as a useful complement to medication and psychotherapy (82). Exercise has effect on depression, in younger people reduced depression symptoms were seen 10 and 30 minutes after a single 30 minutes cycling session. The reduction in depression symptoms was the same independent of light, moderate or hard exercise intensity measured by the Borg scale (83), rating "11", "13" or " $15 "(84)$. In older people, a greater amount of physical activity was associated with reduced depression symptoms (85). In the psychosocial dimension, starting to exercise is a behavioural change, which can reduce depression and negative thoughts. Exercise can have a beneficial social effect by planning the visit, travel to the gym and meeting other people at the gym.

\section{Summary of the prehabilitation studies}

To summarise: education, exercise and a behavioural approach have been evaluated in the four studies of prehabilitation interventions in spinal surgery. The choice of interventions in the prehabilitation studies is in line with guidelines for LBP (9-11). There is strong evidence (level A) that exercise intervention is effective in improving pain, function and return to work in patients with CLBP (86) and have a key role in recently updated guidelines including LBP with sciatica (9-11). The study by Nielsen et al. (67), however, is the first time an exercise intervention has been used in prehabilitation before spinal surgery.

\section{Aspects of how to study low back pain}

LBP is multifactorial and it is necessary to evaluate different perspectives. There are, internationally recommended PROMs for function, pain, and health (87). This provides a thorough biopsychosocial description of the patient cohort and the possibility to compare studies.

Apart from PROMs, pain can be evaluated in different ways. Various tests of somatosensory function can be used to understand the pain mechanisms involved. In the assessment of patients with degenerative lumbar spine disorders, bedside neurological tests are standard. Pain can also be investigated more specifically. 
One alternative is to analyse the somatosensory function of pain by quantitative sensory testing (QST) (88), and this may also contribute to an understanding of the pain mechanisms involved (88). Detection thresholds, pain thresholds, and pain summation among other test for pain sensitivity can be measured by QST (89). Furthermore, QST can detect any gain of sensory function that occurs, in the form of lowered sensory thresholds (in, for example, patients with hyperesthesia and hyperalgesia), and a loss of sensory function (in, for example, patients with hypoesthesia and hypoalgesia) $(89,90)$. Lowered pain thresholds in QST indicate central hyperexcitability (91). This alteration in sensory thresholds can be either localized or widespread, and may be present in non-affected body regions (92).

Another perspective to increase knowledge about LBP is to explore people's perspectives and experiences. In inquiries about patients perspectives of an intervention or how a model of care effects patients qualitative research can contribute to new knowledge and understanding (93). The use of broad open questions makes it possible to explore and catch the expected variety of experiences of $\operatorname{LBP}(93,94)$. Qualitative findings therefore can be useful to feed in aspects for further development of health care processes. 


\section{Rationale of the thesis}

Clinical guidelines recommend that non-surgical intervention to be exhausted before making a decision to undergo spinal-surgery in patients with degenerative lumbar spine disorders. However, there is lack of information to what extend the non-surgical intervention is used and lack of information about the content in nonsurgical interventions. Most of the patients with LDH, LSS, spondylolisthesis or DDD improve after surgery, but 22-39\% are doubtful about or dissatisfied with the results at the 1-year follow-up (15). Pre-surgery physiotherapy can contribute to determine which treatment options are appropriate, and may support the positive effects of surgery. Few studies, however, have evaluated the effects of pre-surgery physiotherapy.

Pre-surgery intervention is a new setting for physiotherapy, and it is for this reason of interest to add a description of patients' experiences to the traditionally used quantitative PROMs. Explorative qualitative interviews can provide new insights and deeper understanding of patient experiences and needs, and may provide information that is needed for the further development of care for this patient group.

A majority of the patients scheduled for spinal surgery have experienced pain for more than 3 months. Persistent pain results from a complex interplay of many factors. Maladaptive neuroplastic changes in the central nervous system can be influenced by orthopaedic structural pathology, biochemical and psychosocial factors (95). Such changes can result in increased pain sensitivity, alteration of somatosensory processes that reduce pain thresholds, or a wider distribution of pain (95). It has been suggested that QST of somatosensory function can contribute to the understanding of pain mechanisms involved (88). Few studies exist, and further knowledge is needed. This reinforces the need for prospective studies that will enable us to study how different pre-surgery pain mechanisms can influence the results of surgery and address the possible need for the additional treatment of pain in conjunction with surgery. Knowledge about pain mechanisms may be important in the development of a stratified treatment process. 


\section{AIMS OF THE THESIS}

\section{Overall aim}

The overall aim of the thesis is to study pre-surgery physiotherapy, and somatosensory function in patients with degenerative lumbar spine disorders, and to explore patients' experiences of pre-surgery physiotherapy.

\section{Specific aims}

To describe somatosensory profiles in patients with degenerative lumbar spine disorders, to identify the proportion with altered somatosensory profile, and to analyze demographic characteristics, self-reported function, pain, and health preand 3 months post-surgery. Paper I

To investigate the association between pain sensitivity in the hand, as a sign of widespread pain pre-surgery, and patient-reported outcomes in function, pain and health pre- and post-surgery in patients with lumbar disc herniation or lumbar spinal stenosis. Paper II and additional analysis with data from PROMs at 1-year follow-up

To study if pre-surgery physiotherapy improves function, pain, and health in patients with degenerative lumbar spine disorders scheduled for surgery. Paper III

To describe patients' experiences of how symptoms are explained, and their experiences of the influences on back-related health after pre-surgery physiotherapy. Paper IV 


\section{METHODS}

\section{Design}

This thesis is based on three studies the results of which were presented in four papers. Table 1 and Figure 2 show an overview of the studies.

Table 1 Overview of the designs, data collection, number of participants and data analysis in the three studies described in the thesis.

\begin{tabular}{|c|c|c|c|c|}
\hline Study & A & & B & C \\
\hline Design & $\begin{array}{l}\text { Paper I } \\
\text { Cross-sectional } \\
\text { and prospective } \\
\text { design }\end{array}$ & $\begin{array}{l}\text { Paper II } \\
\text { Cross-sectional } \\
\text { and prospective } \\
\text { design }\end{array}$ & $\begin{array}{l}\text { Paper III } \\
\text { Randomized } \\
\text { controlled trial }\end{array}$ & $\begin{array}{l}\text { Paper IV } \\
\text { Explorative } \\
\text { qualitative design }\end{array}$ \\
\hline Data collection & $\begin{array}{l}\text { QST; somato- } \\
\text { sensory profile } \\
\text { PROMs; before } \\
\text { and } 3 \text { months } \\
\text { post-surgery }\end{array}$ & $\begin{array}{l}\text { QST; pain } \\
\text { sensitivity in hand } \\
\text { PROMs; before, } 3 \\
\text { months and } 1 \\
\text { year }^{*} \text { post-surgery }\end{array}$ & $\begin{array}{l}\text { PROMs; before } \\
\text { and after pre- } \\
\text { surgery } \\
\text { intervention, } 3 \\
\text { months and } 1 \\
\text { year post-surgery }\end{array}$ & $\begin{array}{l}\text { Semi-structured } \\
\text { interviews after } \\
\text { pre-surgery } \\
\text { physiotherapy }\end{array}$ \\
\hline $\begin{array}{l}\text { Time for } \\
\text { inclusion }\end{array}$ & \multicolumn{2}{|c|}{ September 2013 to December 2014} & $\begin{array}{l}\text { October } 2012 \text { to } \\
\text { March } 2015\end{array}$ & $\begin{array}{l}\text { June } 2014 \text { to } \\
\text { February } 2015\end{array}$ \\
\hline Participants & $\begin{array}{l}\text { Patients with } \\
\text { degenerative } \\
\text { lumbar spine } \\
\text { disorders } \\
\text { scheduled for } \\
\text { spinal surgery }\end{array}$ & $\begin{array}{l}\text { Patients with LDH } \\
\text { or LSS scheduled } \\
\text { for spinal surgery }\end{array}$ & $\begin{array}{l}\text { Patients with } \\
\text { degenerative } \\
\text { lumbar spine } \\
\text { disorders } \\
\text { scheduled for } \\
\text { spinal surgery }\end{array}$ & $\begin{array}{l}\text { Patients who } \\
\text { participated in at } \\
\text { least } 12 \\
\text { physiotherapy } \\
\text { sessions in study } \\
\text { B }\end{array}$ \\
\hline $\begin{array}{l}\text { Number of } \\
\text { participants }\end{array}$ & $\begin{array}{l}105 \\
\text { (55 women) }\end{array}$ & $\begin{array}{l}82 \\
\text { LDH } 29 \text { (15 women) } \\
\text { LSS } 53 \text { (27women) }\end{array}$ & $\begin{array}{l}197 \\
\text { (105 women) }\end{array}$ & $\begin{array}{l}18 \\
\text { (10 women) }\end{array}$ \\
\hline Data analysis & $\begin{array}{l}\text { Unpaired and } \\
\text { paired tests } \\
\text { Z-transformation }\end{array}$ & Linear regression & $\begin{array}{l}\text { Two-way analysis } \\
\text { of covariance and } \\
\text { repeated } \\
\text { measures } \\
\text { Multiple } \\
\text { imputation }\end{array}$ & $\begin{array}{l}\text { Qualitative } \\
\text { content analysis }\end{array}$ \\
\hline
\end{tabular}

QST, Quantitative sensory testing; PROMs, Patient-reported outcome measures; LDH, lumbar disc herniation; LSS, lumbar spinal stenosis. * additional analysis with data from PROMs at 1-year follow-up 
Study A: A cross-sectional and prospective study analysing somatosensory function measured with QST. Papers I, II and additional analysis with data from PROMs at 1-year follow-up post-surgery.

Study B: A randomized controlled trial evaluating pre-surgery physiotherapy. Paper III. A trial protocol was registered on ClinicalTrials.gov (NCT02454400) and published in BMC Musculoskeletal Disorders (96). The study is named "PREPARE".

Study C: An explorative qualitative interview study, with data from patients' participated in pre-surgery physiotherapy in study B. Paper $I V$.

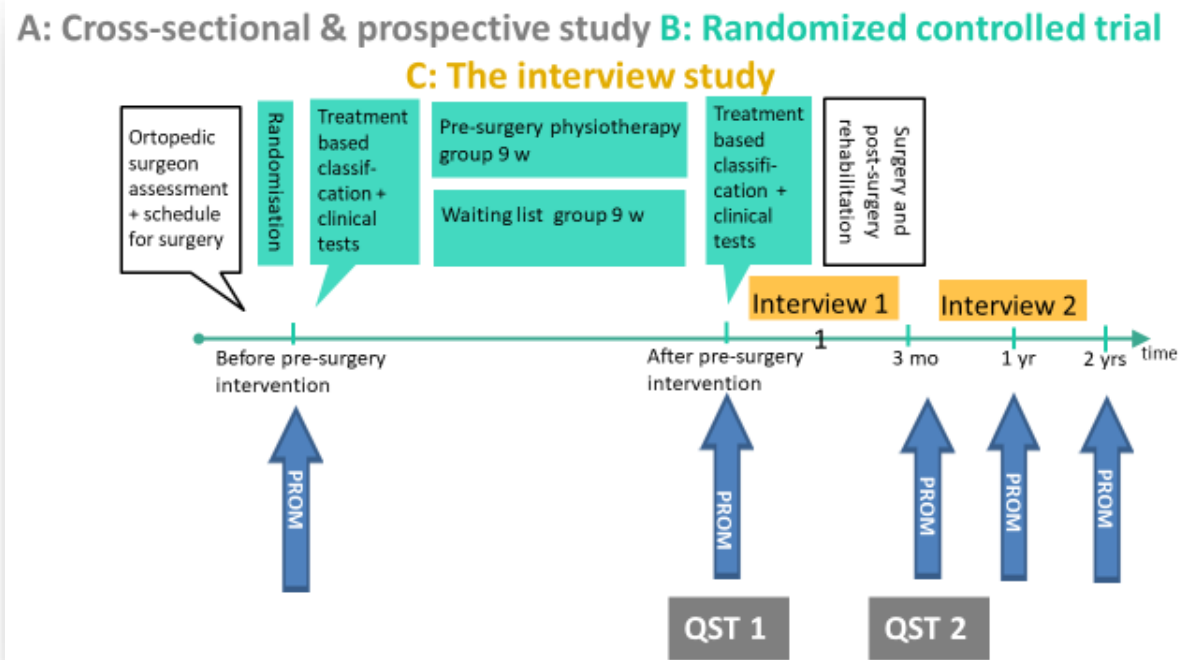

Figure 2 Flow chart of the three studies. All data from the three studies are not presented in the thesis. Quantitative sensory testing (QST).

\section{Participants}

\section{Inclusion}

The inclusion criteria used in studies A and B were: patients aged 25-80 years scheduled for surgery for degenerative lumbar spine disorders; the presence of LBP or leg pain caused by LDH, LSS, spondylolisthesis (grades 1-2), or DDD; a diagnosis confirmed by magnetic resonance imaging; a pain level sufficiently high to indicate surgical intervention; and fluency in Swedish. Exclusion criteria were a need of acute surgery or resurgery on the same level; severe spinal pathology 
(such as osteoporosis or a spine problem treated by fusion at 4 or more levels); or other severe diagnoses.

The participants in study $\mathrm{C}$ were included from study $\mathrm{B}$ with one additional inclusion criterion: having participated in at least 12 physiotherapy sessions.

\section{Study A}

In study A, 105 participants were included, 61 (58\%) of whom were recruited from study B (Figure 3). It was intended that patients with LDH be included, and 18 (41\%) of the newly recruited 44 participants (42\%) had LDH, while 12 (20\%) of the 61 participants recruited from study B had LDH.

The mean age was 60 (SD 13) years and $55(52 \%)$ were women. The population included LSS $(\mathrm{n}=61 ; 58 \%)$, LDH $(\mathrm{n}=30 ; 29 \%)$, DDD $(\mathrm{n}=8 ; 8 \%)$, and spondylolysis/spondylolisthesis $(n=6 ; 6 \%)$ (Table 2). Patients with LSS were significantly older (68 \pm 8 years) than patients with LDH $(48 \pm 11$ years; $\mathrm{P}<$ $0.001)$. A pain duration greater than 2 years was reported by 55 patients $(52 \%)$ and was significantly more common among patients with LSS compared to patients with $\mathrm{LDH}(\mathrm{P}=0.003)$. In study A, 17 eligible patients declined to participate, due to the need for additional visits to the hospital.

In the results presented in paper I, all 105 participants are included. In the results presented in paper II and in an additional analysis with data from PROMs at 1-year follow-up, the 82 participants with the diagnoses LSS $(n=53)$ and LDH $(n=29)$ were included with all data for the PROMs, $47(57 \%)$ of whom had been recruited from study $B$. There were no significant differences between these two different diagnosis populations in gender distribution or in the pre-surgery and post-surgery PROMs. 


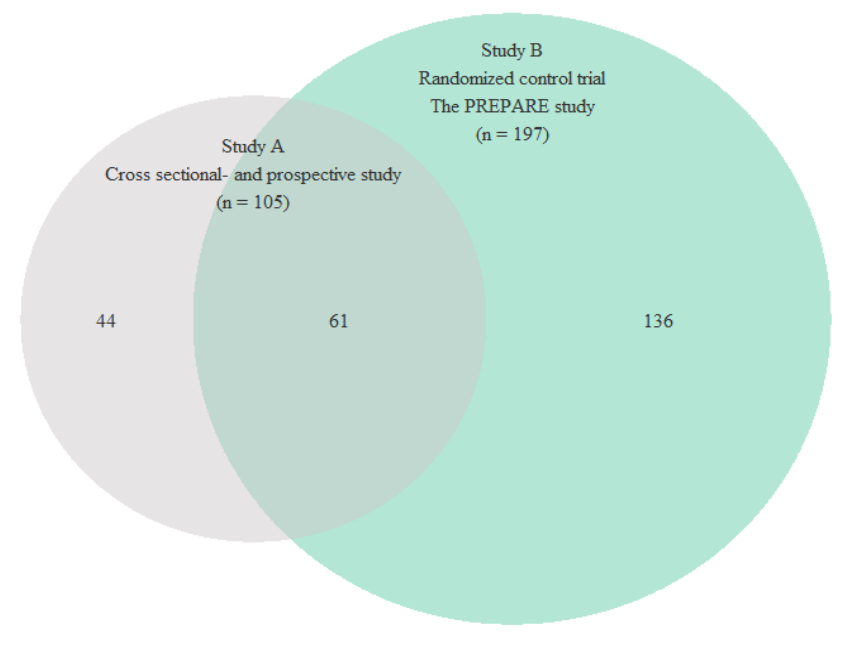

Figure 3 Overview of design and number of participants in studies A and B.

Table 2 Characteristics and patient-reported outcomes measures for participants in study A.

\begin{tabular}{lr}
\hline Characteristics & $\mathrm{n}=105^{\mathrm{a}}$ \\
\hline Age, mean (SD) & $60(13)$ \\
Women, $\mathrm{n}(\%)$ & $55(52)$ \\
Pain duration back/leg > 2 years, $\mathrm{n}(\%)$ & $55(52)$ \\
ODI, mean (SD) & $38(16)$ \\
VAS back pain, mean (SD) & $54(26)$ \\
VAS leg pain, mean (SD) & $61(25)$ \\
EQ-5D, mean (SD) & $0.42(0.3)$ \\
EQ-VAS, mean (SD) & $50(22)$ \\
SF-36 PCS, mean (SD) & $29(9.1)$ \\
SF-36 MCS, mean (SD) & $46(12)$ \\
FABQ-PA, mean (SD) & $15(6.0)$ \\
HADS anxiety, mean (SD) & $6.0(3.8)$ \\
HADS depression, mean (SD) & $4.7(3.3)$ \\
SES, mean (SD) & $130(41)$ \\
Pain drawing $n$ (\%): & $41(40)$ \\
Back and/or unilateral leg pain & $43(42)$ \\
Bilateral leg pain & $19(18)$ \\
Back- leg pain and other pain locations & $19(0)$
\end{tabular}

SD, standard deviation; ODI, Oswestry Disability Index (0-100) (higher score indicate higher disability); VAS, Visual Analogue Scale (0 - 100) (higher score indicate higher pain intensity); EQ-5D (- 0.594 - 1) and EQVAS, EuroQol (higher score indicate better health); HADS, Hospital Anxiety and Depression scale (0 - 21) (higher score indicate more signs of anxiety and depression); SES, Self-Efficacy Scale (0-200) ( higher score indicate better self-efficacy); SF-36 PCS and MCS, Short Form-36 Health related quality of life, Physical and Mental Component Summery score (0 - 100) (higher score indicate better health); FABQ-PA, Fear Avoidance Beliefs Questionnaire - physical activity ( 0 - 24) (higher score indicates higher level of fear avoidance beliefs. a Maximum missing data: $\mathrm{n}=11$ 


\section{Study B}

In study B, 197 participants were included, and assigned to one of two groups by block randomization. For each randomization block, sealed opaque envelopes were prepared with a 1:1 ratio of allocation to the two groups. After baseline measurement, an independent physiotherapist informed the patient the group to which he or she had been allocated. The physiotherapists who performed the physical examination were blinded to the randomization, whereas patients and the treating physiotherapist were not. Of the 197 participants, 105 were women, and the mean (SD) age in the cohort was 59 (12) years. One hundred and nineteen $(66 \%)$ of the participants had had back and/or leg pain for longer than 1 year. Ninety-eight (54\%) had experienced back or leg pain for longer than 2 years. The activity level was reported to be inactive or mildly active for 63 of the participants (34\%) at inclusion (Table 3).

In the preceding 12 months, 115 patients $(58 \%)$ had visited a physiotherapist or other caregiver at least once, $48(42 \%)$ of whom reported that their condition improved, 52 (46\%) unchanged, and 14 (12\%) worsened.

The flowchart in Figure 4 depicts inclusion, the numbers who received the intervention to which they had been allocated, and the loss of PROMs questionnaires. Forty-five participants who were assessed to be eligible chose not to participate. Twenty-four of these participants gave their reason for not participating, while for 21 participants the reason is unknown. The participants were assigned at random to either the physiotherapy group $(n=99)$ or the waitinglist group $(n=98)$ (Figure 4). The only significant difference between the baseline characteristics of the groups was that the score on Short Form-36 Health related quality of life Physical Component Summary scores (SF-36 PCS) was lower in the presurgery physiotherapy group (Table 4). One hundred and sixty-eight patients completed the questionnaire after the pre-surgery intervention. The characteristics of patients who dropped out differed from those who remained only in one characteristic: a larger proportion of patients in the dropout group had $\mathrm{LDH}, \mathrm{n}=$ $13(45 \%)$, than in the remaining group, $\mathrm{n}=27(16 \%),(\mathrm{P}=0.002)$. There were no significant differences between the groups in the type of surgery carried out. The physiotherapy intervention was carried out at one of eleven physiotherapy clinics in the County Council, close to the participant's home. 
Table 3 Characteristics for participants in study B, the randomized controlled trial $(n=197)$.

\begin{tabular}{lrr}
\hline Characteristics & & $(12)$ \\
\hline Age, mean (SD) & 105 & $(53)$ \\
Gender, women $\mathrm{n}(\%)$ & 98 & $(54)$ \\
Pain duration back/leg pain >2 year, $\mathrm{n}(\%)$ total=181 & 18 & $(9)$ \\
Cigarette smoker, $\mathrm{n}(\%)$ & 19 & $(10)$ \\
Prior lumbar spine surgery, not for the same segment, $\mathrm{n}(\%)$ & 13 & $(7)$ \\
$\quad 1$ & & \\
$\quad$ Two or more (number of surgeries 2-5) & 64 & $(34)$ \\
Employment situation, $\mathrm{n}(\%) \mathrm{n}=191$ & 1 & $(0)$ \\
$\quad$ Currently working & 82 & $(43)$ \\
$\quad$ Unemployed & 43 & $(22)$ \\
$\quad$ Retired & & \\
$\quad$ Sick leave and/or retired due to health problems & 28 & $(14)$ \\
Physical activity in the preceding 12 months, $\mathrm{n}(\%) \mathrm{n}=193$ & 35 & $(18)$ \\
$\quad$ Inactive & 88 & $(46)$ \\
Mildly active & 37 & $(19)$ \\
Walking & 5 & $(3)$ \\
Moderately active & & \\
Very active & 129 & $(65)$ \\
Diagnosis, $\mathrm{n}(\%)$ & 40 & $(20)$ \\
$\quad$ Lumbar spinal stenosis & 15 & $(8)$ \\
$\quad$ Lumbar disc herniation & 13 & $(7)$ \\
$\quad$ Spondylolisthesis &
\end{tabular}

Table 4 Mean (SD) of patient-reported outcome measures at baseline for participants in study $\mathrm{B}$, allocated to the physiotherapy- and the waiting-list group.

\begin{tabular}{llllll}
\hline & \multicolumn{3}{l}{ Physiotherapy $(\mathrm{n}=99)$} & \multicolumn{3}{l}{ Waiting-list $(\mathrm{n}=98)$} \\
\hline & Mean & $(\mathrm{SD})$ & 40 & $(\mathrm{SD})$ & P-value \\
\hline ODI & 38 & $(13)$ & 60 & $(22)$ & 0.155 \\
VAS back pain & 56 & $(24)$ & 64 & $(20)$ & 0.264 \\
VAS leg pain & 65 & $(22)$ & 0.356 & $(0.3)$ & 0.670 \\
EQ-5D index & 0.371 & $(0.3)$ & 48 & $(20)$ & 0.720 \\
EQ VAS & 51 & $(18)$ & 27 & $(7)$ & 0.280 \\
SF-36 PCS & 30 & $(7)$ & 44 & $(13)$ & 0.012 \\
SF-36 MCS & 45 & $(13)$ & 16 & $(5)$ & 0.520 \\
FABQ-PA & 16 & $(6)$ & 7 & $(4)$ & 0.993 \\
HADS anxiety & 5 & $(4)$ & 4 & $(3)$ & 0.668 \\
HADS depression & 4 & $(3)$ & 127 & $(31)$ & 0.142 \\
SES & 134 & $(38)$ & & & \\
\hline
\end{tabular}

\section{Bold text $\mathrm{p}<0.05$}

SD, Standard deviation; ODI, Oswestry Disability Index (0-100) (higher score indicates higher disability); VAS, Visual Analog Scale (0-100) (higher score indicates higher pain intensity); EQ-5D, EuroQol (-0.594 to 1) (higher score indicates better health); SF-36 PCS and MCS, Short Form-36 Health related quality of life Physical and Mental health Component Summary scores (0-100) (higher score indicate better health); FABQ-PA, Fear-Avoidance Beliefs Physical Activity (0-24) (higher score indicates more signs of fearavoidance); HADS, Hospital Anxiety and Depression Scale (0-21) (higher score indicates more signs of anxiety or depression); SES, Self-Efficacy Scale (0-200) (higher score indicates better self-efficacy). Data with imputation. 


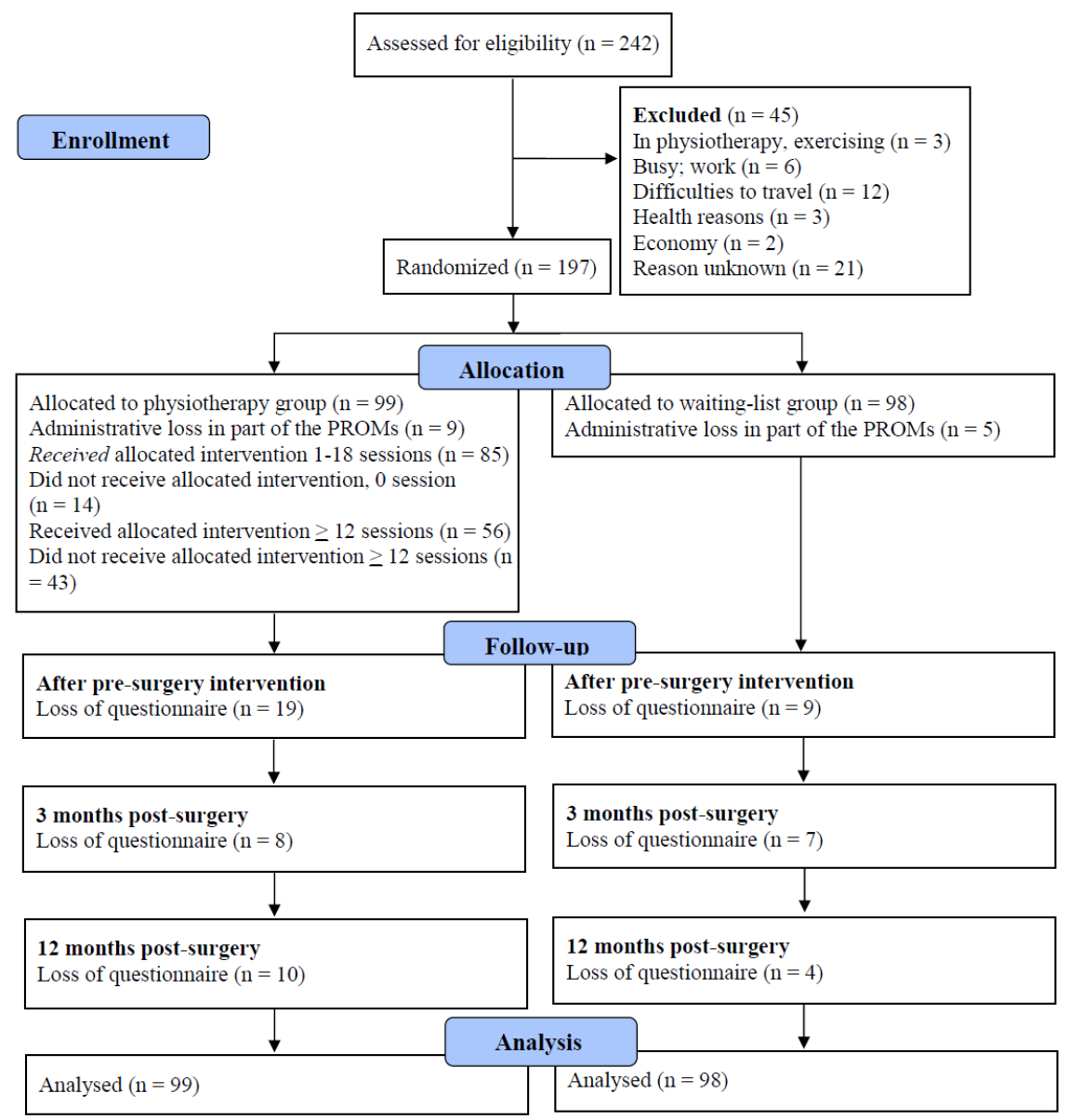

Figure 4 The CONSORT flow chart for study B, the randomized trial.

\section{Study C}

In total, 56 of the participants in study B had participated in at least 12 physiotherapy sessions and 18 of those were included in study C. Consecutive sampling was used and this gave sufficient variation in age, gender and whether the informant lived nearby or far from the physiotherapy clinic. No further purposeful sampling was needed. Our intention was to include at least 15 informants. Inclusion stopped when interviews from the most recently added three participants did not provide new information.

The participants had a median (range) age of 65 (49-74) years, and 10 of the 18 participants were women. Table 5 presents the characteristics of the participants. All 18 who were invited agreed to participate. 
Table 5 Characteristics of participants in study $C$, the qualitative interview study $(n=18)$. The median (range) age was $65(49-74)$.

\begin{tabular}{|c|c|}
\hline Characteristics & $\mathrm{n}$ \\
\hline Gender, women & 10 \\
\hline Cigarette smoker & 0 \\
\hline Did not have surgery & 4 \\
\hline \multicolumn{2}{|l|}{ Prior lumbar spine surgery, not for the same segment } \\
\hline 2 surgeries & 1 \\
\hline \multicolumn{2}{|l|}{ Employment situation } \\
\hline Currently working & 6 \\
\hline Retired & 10 \\
\hline Sick leave and/or retired due to health problems & 2 \\
\hline \multicolumn{2}{|l|}{ Diagnosis } \\
\hline Lumbar spinal stenosis & 15 \\
\hline Lumbar disc herniation & 2 \\
\hline Spondylolisthesis & 1 \\
\hline \multicolumn{2}{|l|}{ ODI* } \\
\hline Minimal disability & 3 \\
\hline Moderate disability & 8 \\
\hline Severe disability & 7 \\
\hline \multicolumn{2}{|l|}{ PGIC** after pre-surgery physiotherapy } \\
\hline Very much better & 0 \\
\hline Much better & 6 \\
\hline Slightly better & 8 \\
\hline Unchanged & 3 \\
\hline Slightly worse & 1 \\
\hline Much worse & 0 \\
\hline Very much worse & 0 \\
\hline
\end{tabular}

\section{Ethical considerations}

The three studies received ethical approval from the Regional Ethics Review Board in Linköping before patients were included. Informed content was obtained from participants in studies A-C before data collection with QST or PROMs took place, and before the interviews were held. In study A, when measuring pain and detection thresholds patients were informed before measurements were made that the measurement process would be stopped immediately when the patient perceived the sensation as painful. There are no known risks associated with the measurements or interventions in the studies. Use of patients' time was also considered. In study A, the QST measurements before surgery were performed in conjunction with the standard appointment with the orthopaedic surgeon, anaesthetist, occupational therapist and physiotherapist before surgery. The same physiotherapist then performed the standard follow-up at 4 or 6 weeks postsurgery. The QST measurements at 3 months post-surgery were booked at an extra 
appointment, but with the same physiotherapist. Some patients wrote questions about their care when answering the PROMs, and these patients were contacted. Some patients had high scores on the depression and/or anxiety scales in the PROMs, and these patients were offered assistance to obtain adequate care.

\section{Data collection}

The data collection for the work described in papers I and II involved QST measurements and the completion by participants of PROMs, for paper III only PROMs (Table 6), and in paper IV interviews and PROMs for ODI before the presurgery physiotherapy, and completion of Patient Global Impression of Change (PGIC) after it.

Table 6 Data collection for work described in papers I-IV

\begin{tabular}{lcccc}
\hline & Paper I & Paper II Paper III Paper IV \\
\hline QST measurements & & & & \\
Cold Detection Threshold (CDT) & $X^{\mathrm{a}}$ & & & \\
Warmth Detection Threshold (WDT) & $\mathrm{X}^{\mathrm{a}}$ & & & \\
Cold Pain Threshold (CPT) & $\mathrm{X}^{\mathrm{a}}$ & $\mathrm{X}^{\mathrm{c}}$ & & \\
Heat pain threshold (HPT) & $\mathrm{X}^{\mathrm{a}}$ & $\mathrm{X}^{\mathrm{c}}$ & & \\
Pressure Pain Threshold (PPT) & $\mathrm{X}^{\mathrm{b}}$ & $\mathrm{X}^{\mathrm{c}}$ & & \\
PROMs & & & & $\mathrm{X}$ \\
ODI & $\mathrm{X}$ & $\mathrm{X}$ & $\mathrm{X}$ & $\mathrm{X}$ \\
VAS back pain & $\mathrm{X}$ & $\mathrm{X}$ & $\mathrm{X}$ & \\
VAS leg pain & $\mathrm{X}$ & $\mathrm{X}$ & $\mathrm{X}$ & \\
Pain drawing & $\mathrm{X}$ & $\mathrm{X}$ & $\mathrm{X}$ & \\
EQ-5D index & $\mathrm{X}$ & $\mathrm{X}$ & $\mathrm{X}$ & \\
EQ-VAS & $\mathrm{X}$ & & $\mathrm{X}$ & \\
SF-36 PCS & $\mathrm{X}$ & & $\mathrm{X}$ & \\
SF-36 MCS & $\mathrm{X}$ & & $\mathrm{X}$ & \\
FABQ-PA & $\mathrm{X}$ & $\mathrm{X}$ & $\mathrm{X}$ & \\
HADS anxiety & $\mathrm{X}$ & $\mathrm{X}$ & $\mathrm{X}$ & \\
HADS depression & $\mathrm{X}$ & $\mathrm{X}$ & $\mathrm{X}$ & \\
SES & $\mathrm{X}$ & $\mathrm{X}$ & $\mathrm{X}$ & $\mathrm{X}$ \\
PGIC & & & & $\mathrm{X}$ \\
Physical activity &
\end{tabular}

${ }^{a}$ Seven body regions: Lower back, thighs and lower legs bilaterally and hand; thenar eminence muscle, and thoracic spine. ${ }^{b}$ Five body regions: Thighs and lower legs bilaterally and hand; thenar eminence muscle, and thoracic spine. ${ }^{\mathrm{c}}$ One body region: hand; thenar eminence muscle. Body regions are described in detail in paper I.

ODI, Oswestry Disability Index (0-100) (higher score indicates higher disability); VAS, Visual Analogue Scale (0-100) (higher score indicates higher pain intensity); EQ-5D, EuroQol (-0.594 to 1) (higher score indicates better health); SF-36 PCS and MCS, Short Form-36 Health-related quality of life, Physical and Mental Health Component Summary scores (0-100) (higher score indicates better health); FABQ-PA, FearAvoidance Beliefs Physical Activity (0-24) (higher score indicates more signs of fear avoidance); HADS, Hospital Anxiety and Depression Scale (0-21) (higher score indicates more signs of anxiety or depression); SES, Self-Efficacy Scale (0-200) (higher score indicates better self-efficacy); PGIC, Patient Global Impression of Change. Physical activity during the preceding 12 months was measured by a question with five answer options; Inactive, Mildly active, Walking, Moderately active, Very active (99) 


\section{Quantitative Sensory Testing}

In study A, a somatosensory profile investigation included the following QST measurements: cold detection threshold (CDT), warmth detection threshold (WDT), cold pain threshold (CPT), heat pain threshold (HPT), and pressure pain threshold (PPT). The QST measurements were carried out one to two weeks prior to surgery by a single investigator, a physiotherapist who was working at the spine clinic. A standardized QST protocol was used with the following procedure (100, 101). The patients were comfortably seated or lying down in a quiet room with an air temperature of $22^{\circ} \mathrm{C}$. At the start of testing, patients were asked to use a VAS (102) to rate the average pain intensity in their back and legs during the preceding two weeks, and their current pain intensity at rest. The patient's more symptomatic side in the back or leg was also registered. The patients reported whether they had been able to refrain from using any strong analgesics during the 24 hours prior to QST, as had been recommended. In cases of analgesic use, the name of the analgesic and the dosage taken were recorded. Each test was initially performed on the non-dominant hand, with the purpose of familiarizing the patient with the QST protocol. These tests were not included in the analysis. The thermal sensory measurements were then performed, and finally the PPT measurements.

\section{Thermal measurements}

QST assesses the function of several types of nerve fibres: small myelinated Adelta fibres that conduct cold sensations and deep pain sensitivity; small unmyelinated $\mathrm{C}$-fibres that conduct warmth, heat pain sensations and deep pain sensitivity (90); and large A-beta fibres that detect light touch (89). CDT and WDT, and subsequently CPT and HPT, were measured using a thermic stimulator (Somedic, Hörby, Sweden) (Figures 5), with a thermode containing a Peltier element with a stimulating area of $25 \times 50 \mathrm{~mm}$. The reproducibilities of measurements of CDT, WDT, CPT, and HPT are high in healthy subjects in repeated testing in the short term (1 week), when detection thresholds are tested before the pain thresholds (103). The reliabilities of pain threshold measurements (CPT, HPT and PPT) are good to excellent for repeated testing in the long-term (4 months) (104). The repeatability is acceptable in patients with sciatica (105).

The thermode was held on the test site during the thermal measurements. The baseline temperature on the thermode was $32{ }^{\circ} \mathrm{C}$, and the temperature was decreased or increased at a rate of $1{ }^{\circ} \mathrm{C} / \mathrm{s}$ over a range of $10-50{ }^{\circ} \mathrm{C}$. The patients were instructed to push a stop button during the measurement of CDT and WDT when they first perceived a decrease in temperature or an increase in temperature, respectively. For CPT or HPT measurements, patients were instructed to push the stop button when the cold or heat sensation, respectively, was first perceived as painful $(100,101)$. Thermal measurements were performed on the following seven 
body regions: lower back ( $2 \mathrm{~cm}$ lateral of the spinal column on the painful side), thighs (lower part of the quadriceps muscle, $7-10 \mathrm{~cm}$ (depending on the width of the participant's hand) above the patella upper border, bilaterally), and lower legs (upper part of the tibialis anterior muscle, $7-10 \mathrm{~cm}$ below the patella lower border, bilaterally), and two body regions that are not affected by degenerative lumbar spine disorders: hand (thenar eminence muscle on the dominant hand), and upper back (on the lower thoracic spine, T 10-12, contralateral to the lower back region measured). The two non-affected body regions were added to detect whether the patient had generalized alteration in sensory profile. Each thermal measurement was repeated five times, and the mean value was calculated for each patient.

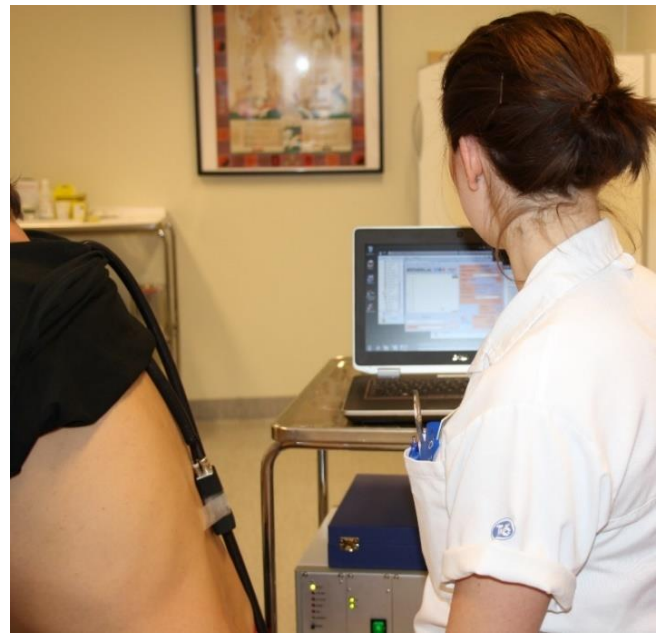

Figure 5 Measurement using the thermic stimulator on lower thoracic area.

\section{Algometer measurements}

PPT was measured using a handheld electronic pressure algometer (Somedic, Hörby, Sweden) (Figure 6) with a probe of diameter $1 \mathrm{~cm}$. The pressure algometer has good reliability $(106,107)$ and validity (106).

The patient was instructed to state when the pressure started to become painful, at which point the applied pressure was released $(100,101)$. Pressure was applied at a rate of $30 \mathrm{kPa} / \mathrm{s}$ up to a maximal pressure of $700 \mathrm{kPa}$. PPT was measured once at each of five body regions, which included the same body regions used for thermal measurements, excluding the two spinal regions. 


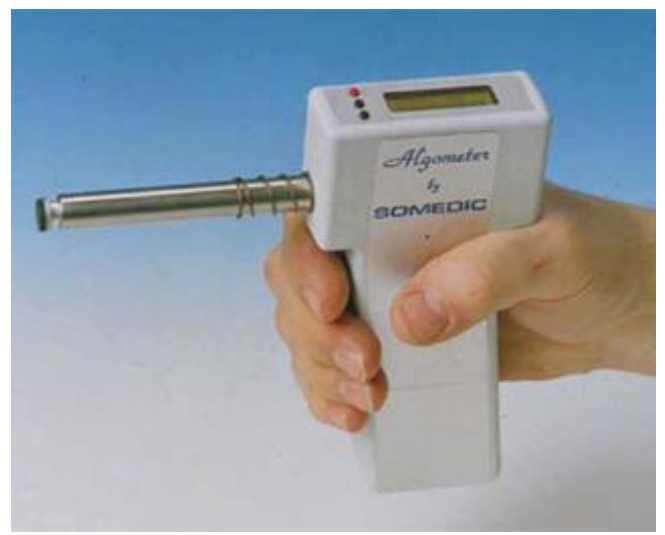

Figure 6 The handheld electronic pressure algometer (Somedic, Hörby, Sweden).

\section{Patient-reported outcome measures}

The participants in studies A and B completed the questionnaire from the Swedish National Spine Register for spinal surgery patients (Swedish spine register) (15) and complementary questionnaires. These instruments provided demographic data and data regarding function, pain, and health. Data used from Swedish spine register includes; ODI, VAS pain, EQ-5D and SF-36 (98). The complementary questionnaires included and presented in the thesis are: pain drawing (108), the Hospital Anxiety and Depression Scale (HADS) (109), the Self-Efficacy Scale (SES) (110), the Fear-Avoidance Beliefs questionnaire (FABQ-PA) (111), PGIC, and questions about lifestyle behaviour. In study A, VAS for back and leg pain were also measured at the two visits for QST.

In study A, PROMs were completed on four occasions: 1-2 weeks before surgery, and 3 months and 1 and 2 years post-surgery, (the result of the 2-year follow-up is not included in the thesis). In study B, PROMs were completed on five occasions: before and after the pre-surgery intervention before surgery, and 3 months and 1 and 2 year post-surgery. Two written reminders and (if needed) one telephone call was used to increase the response rate. Only data regarding function, pain and health (EQ-5D, HADS and SES) were collected at the 3-month followup post-surgery.

\section{Function and activity limitation}

Function and activity limitation was evaluated using ODI, which gives a score of $0-100 \%$ disability (97). This was the primary outcome measure used in study B. The ODI contains ten items that investigate pain-related function impairment and activity limitations, each item having six answer options (97). The ODI has excellent test-retest reliability for patients with LSS who have been treated with physiotherapy (112). 


\section{Pain}

Pain was measured with a VAS (102) and pain drawing (108). The patients rated their pain intensity during the preceding week in the back and legs using a VAS with a horizontal line of length $100 \mathrm{~mm}$, ranging from 0 "No pain" to 100 "Worst imaginable pain" (102). Patients also reported pain duration in the back and legs, with responses that included: "I don't have pain", "Less than 3 months", "3 to 12 months", "1 to 2 years", and "More than 2 years". A pain drawing was used to identify whether patients had unilateral, bilateral, or no leg pain, and to determine the pain distribution in other body regions (108). The ODI and VAS pain scales are recommended instruments for measuring function and pain, respectively, in persistent LBP (87) and after spine surgery (113). They are considered to have the highest validity and responsiveness $(87,113)$.

\section{Health-related quality of life}

Health-related quality of life was evaluated by the EQ-5D $(114,115)$ and SF-36 (116). The EQ-5D includes two scales: the EQ-index and EQ-VAS. The EQ-index covers five dimensions: mobility, self-care, usual activities, pain/discomfort, and anxiety/depression. Each dimension receives a score of 1-3, based on three possible answer options: "No problems", "Some problems", and "Extreme problems". The score range from -0.594 to 1 , where 1 is optimal health. The EQVAS is a vertical scale of length $20 \mathrm{~cm}$ ranging from 0 "Worst imaginable health state" to 100 "Best imaginable health state". The EQ-5D is one of the five most commonly used questionnaires to measure health-related quality of life (87). The mean EQ-5D index is 0.86 in the population of the UK, 0.84 in the population in Sweden, and 0.66 among people in Sweden with LBP (117).

SF-36 (116) includes eight multi-item scales that are summarised as physical and mental health component summary scores (PCS and MCS, respectively) (116). The score range from 0 to 100, where higher score indicates better health. Studies in the general population in Sweden have shown that the reliability, constructbased validity $(118,119)$, and criterion-based validity (120) of the SF-36 are all satisfactory. The levels of responsiveness of the EQ-5D, SF-36 PCS, and SF-36 MCS are medium after lumbar surgery, while the responsiveness of the SF-36 total score is low (113).

\section{Fear avoidance}

Fear avoidance was measured by FABQ, which is a 16-item questionnaire that focusses on a patient's beliefs (111). The FABQ questions comprise a 4-item subscale that describes how physical activity affects the patient's pain (FABQPA). Each item is answered on a 7-grade scale, range from "Do not agree" to "Fully 
agree". The score range from 0 to 24 , where higher score indicates more signs of fear avoidance. The test-retest reliability and internal consistency of the English version of the FABQ are good in patients with CLBP (111), and the internal consistency of the Swedish version is good among patients with whiplashassociated disorder (WAD) (121).

\section{Anxiety and depression}

Levels of anxiety and depression were measured with HADS (109), which includes seven items for anxiety and seven items for depression. The score range from 0 to 21, where higher score indicates more signs of anxiety and depression. The Swedish version of HADS is a robust instrument with regard to reliability, discriminant validity, concurrent validity, and its ability to reveal cases of anxiety and depression (122).

\section{Self-efficacy}

Self-efficacy was evaluated with the SES, which is a 20-item scale that assesses the confidence of a patient with respect to activities of daily living (110). Each item is answered on an 11-grade scale ranging from "Not at all confident" to "Very confident". The score range from 0 to 200, where higher score indicates better selfefficacy. The English version was developed for use in patients with LBP, and its internal consistency is high (110). The Swedish version has been modified to be suitable for use in patients with all kinds of pain (123), and its internal consistency and test-retest reliability are high among patients with WAD (124).

\section{Patient-reported treatment effects}

Patient-reported treatment effects were measured by the PGIC (98). It is a one item measurement where the patients rate their improvement with treatment on a 7 point scale that range from "Very much better", "Much better", and "Slightly better", "No change", "Slightly worse", "Much worse" and Very much worse". PGIC is recommended as core outcome in interventions trials in patients with chronic pain (98).

\section{Lifestyle behaviour}

Lifestyle behaviour was measured using one question about physical activity in the preceding 12 months, where five answer options were given: "Inactive", "Mildly active", "Walking", "Moderately active", "Very active. The question is used in a public health survey by The national board of health and welfare in Sweden (99). 


\section{Qualitative interview}

An interview guide was designed for study $\mathrm{C}$ with broad open-ended questions to encourage the informants to describe and explore their experiences of the phenomenon studied (93, 94). Previous qualitative interview studies with participants who were undergoing physiotherapy were used in the development of the interview guide. Two pilot interviews were conducted to validate the interview guide: the results were discussed in our research group and no major changes were needed.

The main question was: "Can you describe your experience of the physiotherapy you have attended?" Two other broad questions were: "Has the physiotherapy influenced your way of handling your back-related symptoms?", and "Looking back on the treatment period with physiotherapy in its entirety, what do you think about the treatment period?" Other questions posed depended on the responses of the participants, and covered several topics: the ability to fit in physiotherapy with other daily activities, explanations for symptoms and interventions, how back-related symptoms influenced daily life, and whether the participant considered the intervention to be suitable for others. Prompt questions were used to encourage the informants to describe more (94).

The interviews took place 0 to 8 months after the pre-surgery physiotherapy intervention and before surgery (if conducted). All interviews were carried out face-to-face at the spine clinic, and lasted for 50 to 85 minutes. The participants had met the interviewer twice before the interview occasion itself, for treatment-based classification and clinical tests before and after the physiotherapy intervention. Thus, the participants knew that the interviewer was a physiotherapist and part of the research group. They also knew that the interviewer was not employed by the healthcare system, and did not carry out physiotherapy treatment in the study. The interviews were audio-recorded and transcribed verbatim. Patient characteristics and outcomes were obtained from PROMs completed by the patients during study B. 


\section{Interventions}

\section{Pre-surgery physiotherapy and waiting-list interventions}

\section{Waiting-list group}

Patients received standardized information from an orthopaedic surgeon about surgery and post-surgery rehabilitation. They received also standardized advice to stay active.

\section{Pre-surgery physiotherapy group}

Patients received a pre-surgery physiotherapy intervention twice a week for 9 weeks. The programme was multicomponent and included:

1. Active physiotherapy according to a treatment-based classification (TBC) (125);

a. Specific exercises (according to directional preference) and mobilisation, or

b. Motor control exercises, or

c. Traction

2. A tailor-made general supervised exercise programme

3. Behavioural approach to reduce fear avoidance and increase activity level.

Patients received the same standardized information as those in the waitinglist group. The tailor-made general supervised exercise programme aimed to be safe in returning to everyday activities. The content of the exercise programme included 10 minutes intervals of cardiovascular exercise at the beginning, in the middle, and at the end of each session. It included a further 5-6 exercises based on the function, posture and patient specific functional scale of the patient (PSFS) (126), with a dosage of 15 repetitions in three sets. It was recommended that exercise equipment be varied, and to consider different starting positions and that some exercises standing upright were included. Further, it was recommended that at least one exercise was altered every third visit, both to provide a distractive pain-coping strategy and to progress the exercise. One definition of progression of exercise used in resistant training is: the act of moving forward or advancing towards a specific goal over time until the target goal has been achieved (76). In the exercise programme the Borg Scale (83) was used to rate the perceived exertion of each exercise session. The prescribed level of exertion for each exercise session was 12-13 on the Borg Scale. A patient who scored lower than 12-13 on the Borg scale was requested to increase the intensity of the exercises. The patients also received written and illustrated descriptions of the exercises and their dosage in the exercise programme. 
The behavioural approach aimed to reduce maladaptive pain behaviours. The behavioural approach included goalsetting, where PSFS (126) was used at the first visit and three follow-ups. It also included strategies to minimize barriers for goal attainment which included for example; information intended to decrease the fear of movement (127), ergonomics, postural alignment and explanatory models for treatment. At home, the patients completed a logbook of self-mediated home exercise and general physical activities.

The physiotherapists who delivered the intervention programme were trained by two specialised physiotherapists in two initial meetings and three follow-up meetings during the study. The physiotherapist followed a checklist for each patient that described the treatment and progression planned for each physiotherapy session, modified to suit the particular patient. A treatment demarcation table was provided to the treating physiotherapists that outlined the content of the intervention. Checklists and logbooks provided data about adherence. If the adherence of a patient started to decline, the physiotherapist urged the patient to continue the intervention programme. If this was not successful, the reason that the patient had stopped the programme was noted. The treating physiotherapists were asked to contact a physiotherapist at the spine clinic that could answer if there were any questions about the intervention or the patients' ability to perform it.

\section{Spinal surgery and post-surgery rehabilitation}

Spinal surgery and post-surgery rehabilitation were carried out according to standard clinical procedures (21). Both groups underwent the same post-surgery rehabilitation, which included feedback on posture and walking, a home exercise programme, and daily walking. The rehabilitation was followed up after 4-6 weeks and the rehabilitation programme modified to include more intensive exercises. 


\section{Analysis}

\section{Statistical analysis}

Table 7 presents the statistical analyses used in papers I-III.

Table 7 Statistical analyses applied in papers I-III.

\begin{tabular}{lccc}
\hline & \multicolumn{2}{c}{ Study A } & Study B \\
\hline & Paper I & Paper II & Paper III \\
\hline Descriptive statistics & $\mathrm{X}$ & $\mathrm{X}$ & $\mathrm{X}$ \\
Nonparametric & $\mathrm{X}$ & $\mathrm{X}$ & $\mathrm{X}$ \\
$\quad$ Mann-Whitney $U$ test & $\mathrm{X}$ & $\mathrm{X}$ & $\mathrm{X}$ \\
Chi-square test & $\mathrm{X}$ & & \\
$\quad$ Fisher exact probability test & $\mathrm{X}$ & $\mathrm{X}$ & $\mathrm{X}$ \\
Parametric & & & \\
$\quad$ Unpaired Student's $t$-test & & $\mathrm{X}$ & \\
Regression & & & \\
$\quad$ Linear regression & & & $\mathrm{X}$ \\
Analysis of covariance & & & \\
Two-way analysis of covariance and & & & $\mathrm{X}$ \\
repeated measures & & & $\mathrm{X}$ \\
Effect size & & & $\mathrm{X}$ \\
Cramer $V$ & & & $\mathrm{X}$ \\
$\quad$ Cohen $d$ & & & \\
Minimal clinically important change (MCIC) & & \\
$\quad$ Minimal detectable change (MDC) & & & \\
Optimal cutoff point (OCP) & & &
\end{tabular}

\section{Study $A$}

In paper I the data from the participants' somatosensory profiles were compared with reference data obtained from healthy subjects from studies by the German Research Network on Neuropathic Pain (DFNS) $(128,129)$. In order to do the comparisons, all QST data were standardized by Z-transformation, in which each QST value is matched for age and gender in the reference values (89). The following expression was used for the Z-transformation:

$Z$-score $=\left(\mathrm{X}_{\text {single patient }}-\right.$ Mean $\left._{\text {references }}\right) / \mathrm{SD}_{\text {references }}$

A Z-score less than -2 or greater than 2 is outside of the $95 \%$ confidence interval (CI) of a normal standard distribution for healthy subjects (89). Moreover, a Z-score less than 0 corresponds to the loss of sensory function, while a Z-score greater than 0 corresponds to a gain of sensory function (89). 
An altered somatosensory profile was defined as having two or more body regions including a normally non-affected body region, i.e., the hand and/or upper back with a Z-score lower than -2 or greater than 2 compared to reference data for CDT, WDT, CPT, HPT or PPT. Including body regions that are not normally affected by degenerative lumbar spine disorders provided an indirect indicator of generalized altered pain sensitivity, within the definition of an altered sensory profile.

In paper II and additional analysis with data from PROMs at 1-year followup, linear regression was used to analyse the associations between pain thresholds (independent variables) in the hand (a non-affected body region) and patientreported measures (dependent variables). All models were adjusted for age and gender.

\section{Study $B$}

A sample size calculation was performed. Based on a Minimally Clinical Important Change (MCIC) of $10 \%$ on the ODI (130) a standard deviation for the $\mathrm{ODI}=20$, a significance level of $\mathrm{P}=0.05$, and a power of $80 \%$, an estimated 64 patients were required in each of the intervention groups.

For between-group comparisons of demographic data, the unpaired Student's $t$-test or Mann-Whitney $U$ test for continuous variables and the Chi-Square test for categorical variables were used. Two-way analysis of covariance and repeated measures (where the covariates were age, gender, and diagnosis) were used for comparisons over time. The analysis of covariance was adjusted for baseline values for each PROM. Cohen's $d$ effect sizes were also calculated for changes in groups over time, whereas Cohen's $d=0.20$ is considered a small, $d=0.50$ is a medium and $d=0.80$ to infinity is a large effect size (131). For Chi-Square test with 4 degrees of freedom, Cramer's $\mathrm{V}=0.05$ is considered a small, $\mathrm{V}=0.15$ is a medium and $\mathrm{V}=0.25$ is considered a large effect size in the analysis of activity level in the two groups (131).

Two-way analysis of covariance and repeated measures require participant data at each time point of the measurement sequence. Data collected at different time points were analysed according to the intention-to-treat principle. Missing data were supplied by imputation, in order to maintain the power of the analysis. Missing data in the PROMs, except for physical activity level and PGIC, were replaced through multiple imputation, based on group data from baseline and from the relevant time point. The process of multiple imputation by chained equations is known as the "fully conditional specification" method in the SPSS statistics package (Version 23.0, IBM Corp, Armonk, NY, USA) (132). Constraints were applied for each variable according to the range of each scale. The mean of 10 
imputation sets was used for each of the PROMs. A sensitivity analysis that compared the per-protocol data with the intention-to-treat data (132) showed no significant differences between these datasets. The study-specific MCIC was calculated by minimal detectable change (MDC) and optimal cutoff point (OCP) for PROMs. The change within the group was determined after the pre-surgery intervention (133). The MDC was calculated using the standard error of the mean (SEM): $1.96 * \sqrt{ } 2 *$ SEM. Further, the PGIC was dichotomised into "Improved" (corresponding to the responses "Very much better", "Much better", and "Slightly better") and "No change". The dichotomised PGIC was used in calculating the sensitivity and specificity for the receiver operating characteristic curve. The OCP was defined as the point at which the combined sensitivity and specificity was highest, with the lowest percentage of misclassified individuals (133). An area under the curve greater than or equal to 0.70 shows that the accuracy of the model is satisfactory (134).

\section{Content analysis}

Qualitative content analysis was chosen when the goal of the work presented in paper IV was to describe and to gain an understanding of patients' experiences of a phenomenon $(93,135)$. Hsieh and Shannon define qualitative content analysis as "a research method for subjective interpretation of the content of text data through the systematic classification process of coding and identifying themes and patterns" (135). The data was analysed in an iterative process that used both inductive and deductive content analysis. The data was first analysed inductively, because knowledge of the phenomenon studied was limited (135). All transcripts were read repeatedly to get a sense of the content. They were then read in more detail to discover "codes", which is the term used to denote text that seems to capture key thoughts. The codes were organized into subcategories based on their relationships to each other. The subcategories were then deductively sorted into categories inspired by the biopsychosocial model (7), which is the model that had been used when designing the intervention used in study B. Trustworthiness was enhanced by the use of quotations showing that the data accurately represent the information that the participants provided (93). The following procedure was used to ensure the credibility of the analyses and their internal validity. The first author coded all transcripts and determined the initial subcategories for them. The other two authors coded three transcripts each. The codes, subcategories and categories were defined during discussion and negotiation between the three authors. The results were discussed in a seminar with researchers from different research fields including researchers experienced in qualitative methodology. 


\section{RESULTS}

\section{Somatosensory function measured by Quantitative sensory testing}

\section{Somatosensory profile of patients on a group level compared to reference data} On a group level, all QST measurements of the somatosensory profiles of the patients had mean $\mathrm{Z}$-score values between -2 and 2 . The group values, thus, lay within the $95 \%$ CI levels of the reference data. Patients had not altered somatosensory profiles at a group level.

\section{Altered somatosensory profile}

A total of 23 patients (22\%) had altered somatosensory profiles for at least one QST measurement in the hand or upper back, and at least one additional body region (Table 2). Of the 23 patients with altered somatosensory profiles, $19(83 \%)$ had Z-scores lower than -2 in one of the QST measurements in at least two body regions compared to the reference data, which shows that they had loss of sensory function. The remaining four patients $(4 \%)$ with altered somatosensory profiles had Z-scores greater than 2 compared to reference data, which shows that they had gain of sensory function and were more sensitive in one test in at least two body regions. The QST measurement CPT did not have Z-score lower than -2, all other QST measurements (CDT, WDT, HPT and PPT), had Z-scores exceeding the limits of -2 or +2 .

\section{Patient-reported outcome measures in patients with or without an altered somatosensory profile}

The 23 patients with altered somatosensory profiles were significantly older than the other 82 patients $(\mathrm{P}=0.031)$ (Table 6$)$. Eighteen of these patients were women and five men, which is a significant difference $(\mathrm{P}=0.005)$. Patients with an altered somatosensory profile reported significantly higher back and leg pain VAS ( $\mathrm{P}=$ 0.016, 0.020), and lower SF-36 MCS $(\mathrm{P}=0.004)$ pre-surgery, than the other patients. There were no significant post-surgery differences between the groups. Pain drawings made pre-surgery showed that patients with an altered somatosensory profile had a larger distribution of pain than other patients in the cohort $(\mathrm{P}=0.047)$. 


\section{Associations between pain sensitivity in hand and patient-reported outcome measures before, 3 months and 1 year post-surgery in patients with lumbar disc herniation or spinal stenosis}

\section{Patients with lumbar disc herniation}

In patients with LDH, an association existed between PPT and ODI (Standardized beta $\beta-0.71, P=0.006)$ pre-surgery. Associations also existed between PPT and the two subscales of HADS (anxiety and depression) $(\beta-0.46$ and $-0.82, P=0.043$ and $\mathrm{P}<0.001$, respectively) and association with $\operatorname{SES}(\beta 0.69, \mathrm{P}=0.017)$ presurgery. An association also existed between PPT pre-surgery and ODI ( $\beta-0.57$, $\mathrm{P}=0.020) 3$ months post-surgery. Furthermore, PPT pre-surgery was associated with VAS leg pain $(\beta-0.56, \mathrm{P}=0.036)$ and $\operatorname{SES}(\beta 0.92, \mathrm{P}<0.001) 3$ months post-surgery. PPT pre-surgery was associated with VAS EQ-5D $(\beta 0.60, \mathrm{P}=$ $0.037)$, HADS depression $(\beta-0.65, \mathrm{P}=0.022)$ and $\operatorname{SES}(\beta 0.67, \mathrm{P}=0.022) 1$ year post-surgery.

To summarize the results for PPT, patients more sensitive to PPT pre-surgery was associated with:

- higher ODI and HADS anxiety and depression and lower SES pre-surgery

- $\quad$ higher ODI and VAS leg pain and lower SES 3-months post-surgery

- higher HADS depression, lower VAS EQ-5D and SES 1 year post-surgery

There was one association between CPT pre-surgery and ODI pre-surgery $(\beta 0.48$, $\mathrm{P}=0.017)$. Associations also existed between CPT pre-surgery and ODI ( $\beta 0.58$, $\mathrm{P}=0.002)$ and VAS back pain and leg pain $(\beta 0.65$ and $\beta 0.53, \mathrm{P}=0.001$ and $\mathrm{P}=$ 0.009 , respectively) 3 months post-surgery. Furthermore, an association existed between CPT pre-surgery and SES $(\beta-0.74, \mathrm{P}<0.001) 3$ months post-surgery. CPT pre-surgery was associated with ODI $(\beta 0.66, \mathrm{P}=0.001)$, VAS back and leg pain ( $\beta 0.65$ and $0.52, \mathrm{P}=0.001$ and $\mathrm{P} 0.012$, respectively), HADS depression $(\beta$ $0.61 \mathrm{P}=0.003)$ and SES $(\beta-0.71, \mathrm{P}=0.001) 1$ year post-surgery.

To summarize the results for CPT, patients more sensitive to CPT pre-surgery was associated with:

- $\quad$ higher ODI pre-surgery

- higher ODI and VAS back and leg pain and lower SES 3 months postsurgery

- higher ODI and VAS back and leg pain and HADS depression and lower VAS EQ-5D and SES 1 year post-surgery

No associations existed between HPT pre-surgery and PROMs pre- and postsurgery. 


\section{Patients with lumbar spinal stenosis}

In patients with LSS, there were no associations between PPT and the PROMs presurgery. One association existed between PPT pre-surgery and HADS anxiety ( $\beta$ $0.67, \mathrm{P}=0.001) 3$ months post-surgery, describing that patients more sensitive to PPT pre-surgery was associated with higher HADS anxiety 3 months post-surgery. There were associations between CPT pre-surgery, and HADS anxiety $(\beta 0.34, \mathrm{P}$ $=0.014)$ pre- surgery and $(\beta 0.33, \mathrm{P}=0.025)$ post-surgery, meaning that patients more sensitive to CPT pre-surgery, was associated with higher HADS anxiety presurgery and 3 months post-surgery. PPT and CPT had no associations with PROMs 1 year post-surgery.

No associations existed between HPT pre-surgery and PROMs pre- or postsurgery. 


\section{Pre-surgery physiotherapy - patient-reported outcome measures}

The patients in the pre-surgery physiotherapy group had an average of 11 treatment sessions, 43 (43\%) of these patients did not complete at least 12 treatment sessions (Figure 3). No adverse events were reported.

\section{Between-group and within-group comparisons}

Between-group comparison after the pre-surgery intervention (before surgery) showed significant differences in ODI, VAS back pain, EQ-5D, EQ-VAS, FABQPA, SES HADS depression, with advantage for the physiotherapy group. Both groups were improved in all PROMs at the two post-surgery time points, but without significant differences between the groups (Table 8).

After the pre-surgery intervention (before surgery), the pre-surgery physiotherapy group was significantly improved in ODI, VAS back and leg pain, EQ-5D, EQ-VAS, and SF-36 PCS compared with baseline. The waiting-list group was significantly improved in VAS leg pain and had deteriorated in HADS depression and SES (Table 8).

The changes in ODI, VAS back and leg, EQ-5D, EQ-VAS, SF-36 PCS, and FABQ-PA were larger than the MDC in the physiotherapy group and the changes in VAS back and leg, EQ-5D, EQ-VAS, and FABQ-PA were larger than the OCP. The deterioration in the waiting-list group was larger than the MDC in HADS depression, smaller than the MDC in SES, while changes in both HADS depression and SES were smaller than the OCP. In four of the PROMs in the pre-surgery physiotherapy group with significant improvements after pre-surgery intervention, the area under the curve was greater than 0.7 for ODI, VAS leg pain, FABQ-PA, and SF-36 PCS (Table 9).

More patients in the physiotherapy group reported a higher physical activity after the pre-surgery intervention than in the waiting-list group $(\mathrm{P}<0.001)$, with a large Cramer V effect size of 0.391 (131). The difference between the groups remained at the 1-year follow-up $(\mathrm{P}=0.020)$, with a large Cramer V effect size of $0.26(131)$.

More patients in the physiotherapy group than in the waiting-list group reported improvements in PGIC at the time point after the pre-surgery intervention (before surgery) $(\mathrm{P}<0.001)$. In the physiotherapy group, $49 \%$ reported that their condition had "Improved," compared with $17 \%$ in the waiting-list-group. Thirteen percent reported that their condition was "Worse", to be compared with $42 \%$ in the waiting-list group. There were no differences between the groups at the 3-month and 1-year follow-ups. 


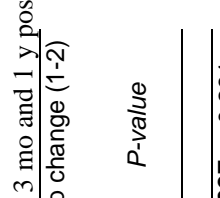

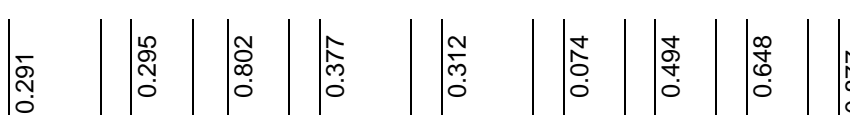

ลิณณ :

$-10$

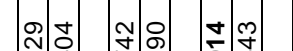

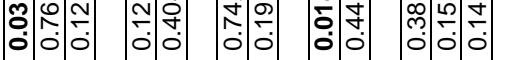

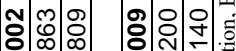

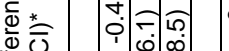

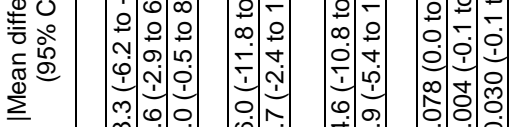

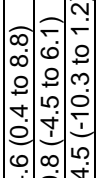

ب.

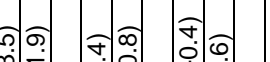

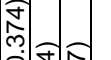

ชิ

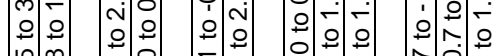

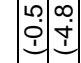

r.

ขึ:

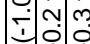

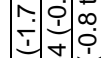

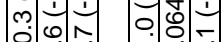

○ं 00 :

ఏ்

包

苞 $\quad \frac{\Phi}{\omega} \cdot \frac{N}{\omega}$

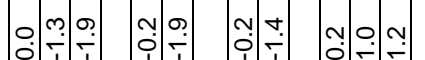

$-0.0$

พִ̣

-

○)

กิกิตั

กิ

을

งิ 10

ㄱ:

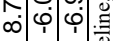

ڤี

产 $\overline{0}$ ல़

Qิ宀

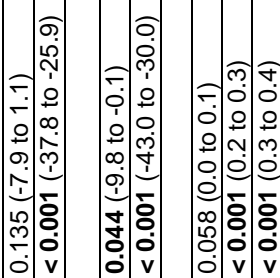

$\widehat{ิ ล}$

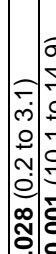

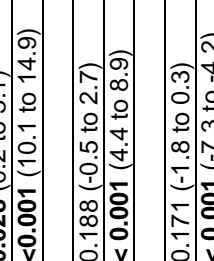

כ)

oิ

1의 0

우 $N$

ธิํํ.

m $0.0 \quad 0.0$

이

듕ㅎㅇㅇㅛ

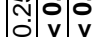

เกำ

Шั

苛

들

조ำ

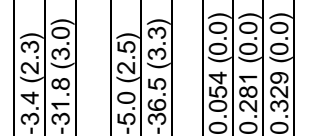

ชิซ

กิ

ลิติซ ลิง

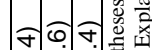

$\sum \frac{\pi}{0}$ 잉

co

$\infty 0$

ט.

$\begin{array}{lll}1 & = \\ - & 0\end{array}$

$\infty$

의응

의의

ง

可

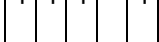

है.

एँ

वै) 월

린

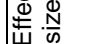

m.

m)

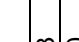
(

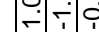

ம่

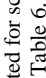

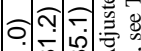

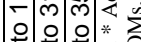

$\checkmark$ ก

은드

< 횽ㅎㅇ

이일

(1)

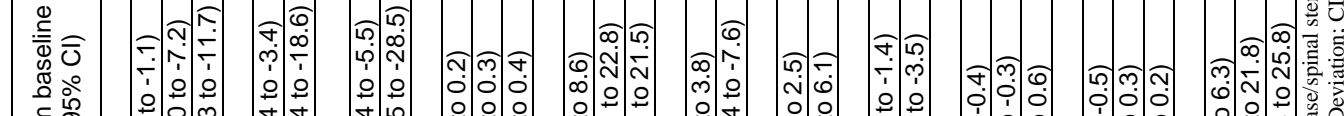

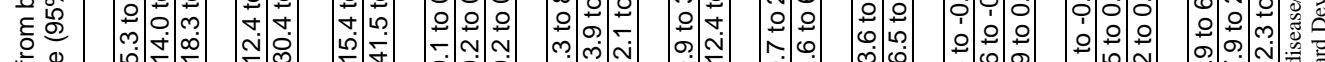

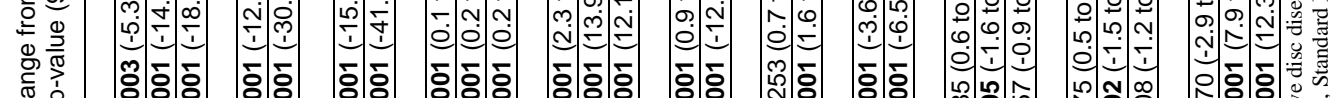

든

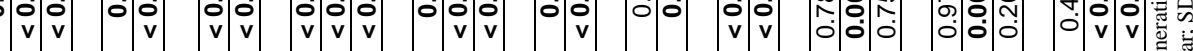

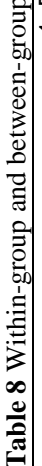

凹

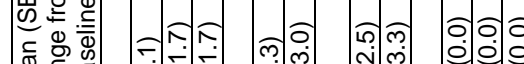

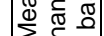

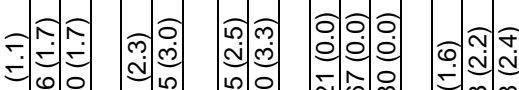

กำำ

@̦:

น 이 స

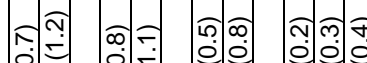

ลิติช

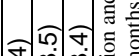

군

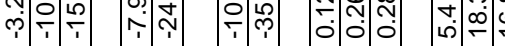

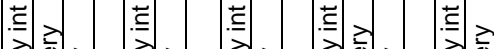

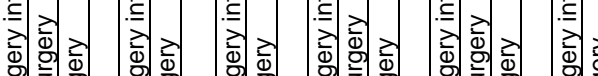

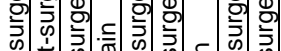
क人

을 包 인

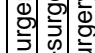

원

인 궁

엥

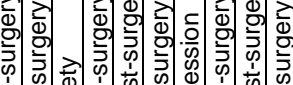

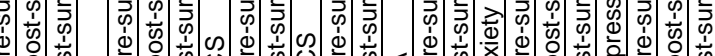

పे 亲 $\begin{aligned} & \varepsilon \\ & m\end{aligned}$

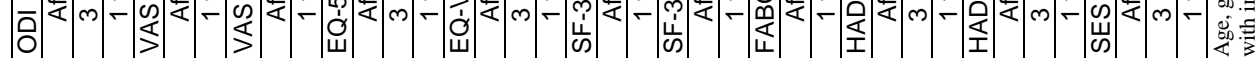


Table 9 The significant mean changes in PROMs after the pre-surgery intervention in comparison to minimal detectable change and optimal cutoff point of minimal clinical important change.

\begin{tabular}{|c|c|c|c|c|c|}
\hline & \multicolumn{5}{|l|}{ Physiotherapy $(n=99)$} \\
\hline & Mean (SE) change from baseline & MDC & $\mathrm{OCP}$ & (Sens; Spec) & AUC (P-value) \\
\hline ODI & $-3.2(1.1)$ & 2.9 & 3.3 & $(0.62 ; 0.70)$ & $0.72(<0.001)$ \\
\hline VAS back pain & $-7.9 \quad(2.3)$ & 6.3 & 7.0 & $(0.70 ; 0.56)$ & $0.68(<0.001)$ \\
\hline VAS leg pain & $-10.5 \quad(2.5)$ & 6.8 & 7.8 & $(0.72 ; 0.64)$ & $0.75(<0.001)$ \\
\hline$E Q-5 D$ & $0.121 \quad 0.0)$ & 0.08 & 0.07 & $(0.62 ; 0.55)$ & $0.59(0.066)$ \\
\hline EQ-VAS & $5.5 \quad(1.6)$ & 4.4 & 4.5 & $(0.64 ; 0.52)$ & $0.65(<0.001)$ \\
\hline SF-36 PCS & $-2.4 \quad(0.7)$ & 2.0 & 2.7 & $(0.70 ; 0.68)$ & $0.76(<0.001)$ \\
\hline \multirow[t]{3}{*}{ FABQ-PA } & $-2.5 \quad(0.5)$ & 1.5 & 1.9 & $(0.65,0.61)$ & $0.70(<0.001)$ \\
\hline & Waiting-list ( $n=98)$ & & & & \\
\hline & Mean (SE) change from baseline & MDC & $\mathrm{OCP}$ & (Sens; Spec) & AUC (P-value) \\
\hline HADS depression & $1.0^{\wedge}(0.2)$ & 0.67 & 1.5 & $(0.71 ; 0.49)$ & $0.61(0.037)$ \\
\hline SES & $-5.7^{\wedge} \quad(2.4)$ & 6.6 & 7.5 & $(0.72 ; 0.60)$ & $0.68(0.001)$ \\
\hline VAS leg pain & $-5.0 \quad(2.5)$ & 6.8 & 7.8 & $(0.72 ; 0.64)$ & $0.75(<0.001)$ \\
\hline
\end{tabular}

$\wedge$ deterioration, SE, Standard error; MDC, Minimal Detectable Change; OCP, Optimal Cutoff Point; Sens, sensitivity; Spec, specificity; AUC, Area Under the Curve. ODI, Oswestry Disability Index (0-100) (higher score indicate higher disability); VAS, Visual Analogue Scale (0 - 100) (higher score indicate higher pain intensity); EQ-5D (- 0.594 - 1) and EQ-VAS, EuroQol (higher score indicate better health); FABQ-PA, Fear Avoidance Beliefs Questionnaire - Physical Activity (0 - 24) (higher score indicates higher level of fear avoidance beliefs HADS, Hospital Anxiety and Depression Scale (0 - 21) (higher score indicate more signs of anxiety and depression); SES, Self-Efficacy Scale (0-200) ( higher score indicate better self-efficacy). 


\section{Pre-surgery physiotherapy - patients' experiences}

Patients' experiences of how symptoms are explained and their experiences of the influences on back-related health after pre-surgery physiotherapy

Five categories of informant experiences were identified (Table 10). Quotations are reproduced below in italics, with comments by the author in parentheses. Respondents are identified by numbers in parentheses.

Table 10 Categories and subcategories used to describe how symptoms are explained, and patients' experiences of the influences on back-related health after pre-surgery physiotherapy.

\begin{tabular}{|c|c|}
\hline Categories & Subcategories \\
\hline $\begin{array}{l}\text { 1. Influences on symptoms, } \\
\text { physical function and sleep }\end{array}$ & $\begin{array}{l}\text { 1A Pain and numbness } \\
\text { 1B Physical function and sleep }\end{array}$ \\
\hline $\begin{array}{l}\text { 2. Influences on coping and } \\
\text { well-being }\end{array}$ & $\begin{array}{l}\text { 2A Feelings of stress, fear and insecurity } \\
\text { 2B Ability to manage symptoms } \\
\text { 2C An opportunity to reflect on interventions }\end{array}$ \\
\hline $\begin{array}{l}\text { 3. Explanations of back- } \\
\text { related symptoms and } \\
\text { wanting to be well-informed }\end{array}$ & $\begin{array}{l}\text { 3A The symptom is mainly an injury in the spine } \\
\text { 3B The symptoms can be influenced by exercises } \\
\text { 3C Searching for feelings of trust to the spine } \\
\text { 3D Strategies to become well-informed about symptoms } \\
\text { 3E Uncertainty how intervention can influence symptoms }\end{array}$ \\
\hline $\begin{array}{l}\text { 4. Influences on social } \\
\text { functioning }\end{array}$ & $\begin{array}{l}\text { 4A Daily routines, work and social role } \\
\text { 4B Longing for a more active life }\end{array}$ \\
\hline $\begin{array}{l}\text { 5. The ability of the model of } \\
\text { care to influence reassurance } \\
\text { and prevention }\end{array}$ & \\
\hline
\end{tabular}

\section{Influences on symptoms, physical function and sleep}

Influence on pain and numbness were described, from complete disappearance or decreased to little or no change. Less frequent use, discontinuation of strong or all analgesics due to reduced pain, and improved ability to handle the pain were reported. Two descriptions of the relief of symptoms, although they still fluctuate;

"It was already after a few, only three or four sessions that the leg problem at least partly went away. Then it could come back sometimes, but not like it was last summer and autumn when it was terrible." (16)

"No, it was just that I noticed that I didn't have as much pain anymore. And I'm taking significantly fewer tablets." (17) 
Experiences of various degree of change from being deconditioned because of pain and limited function during recent years, to improvements in walking quality and distance, strength, ability to more easily change position and remain in a less painful posture, as well as minor or no changes after pre-surgery physiotherapy. Improved sleep and decreased need of rest were also experienced, as described here;

"Yes, because I could sleep maybe 10 hours during the night... and even then I had to rest two or three hours in the afternoon, yes, and now I don't have that need at all...." (15)

\section{Influences on coping and well-being}

The back-related symptoms had earlier caused feelings of fear in activities. Presurgery physiotherapy contributed to feelings of security and an ability to do activities more freely and with confidence, as one informant expressed it;

"I had to have someone with me because my back often locked up, so I couldn't move. But now I'm not afraid to walk by myself, which I think is great." (10)

Exercises helped to reduce feelings of stress and negative thoughts and improved feeling of well-being;

"It's not just the pain that gets less, but also that I feel much, well my whole life, becomes much, much better. The situation, or environ-...well joy of life, or how should I put it?" (17)

"That was what got me going. Yes, *giggles* both physically and mentally that you feel that you are strengthened by it (exercise), that you don't sink deeper *giggles* because you have pain it, it is hard, sort of, to get yourself out of it maybe...." (12)

Experiences of an improved ability to cope with symptoms, greater knowledge about the pain, and the discovery that it is not dangerous to move with some pain. Other examples were: using postural or specific exercises to manage symptoms, being more attentive while performing activities and during periods of intense pain, medication was required, to be able to be more active.

"But otherwise, *h* walking and moving around and so on isn't dangerous, that's what I think. *giggle* Then someone can argue that it is, but I don't think it's dangerous." (14)

"When I feel that it starts to hurt or when I feel unsteady; then I know that I can use an exercise, by leaning slightly forward, or like put the forces in a certain way. Ifeel stable then and it feels good. It is a very good exercise." (7)

Experiences of a change in thinking, from previously wanting surgery as soon as possible, to feeling comfortable doing pre-surgery physiotherapy while being on the waiting list were expressed. This was linked to a feeling that the symptoms were not as acute as before. Other reflections were: feeling better being active with 
exercises compared to being inactive, and exercises helping to feel better mentally. Reflections on improvements led to confidence in the intervention and decisions to extend the timeframe for exercising before a final decision about surgery, as well as cancelling scheduled surgery.

"So now I have expectations that this last thing will also start to go away, but I don't know if it ever will... And of course, if with a little focus and physiotherapy, and if I'm a bit careful, I can come back to a position where I feel quite good, then I don't want to take the risks (of surgery)." (6)

Reflections that an inactive lifestyle was negative and that exercising must be undertaken regularly to maintain its effect led to a plan for lifestyle changes and the resumption of exercise after surgery.

\section{Explanations of back-related symptoms and wanting to be well-informed}

Informants described that the back-related symptoms were linked to the anatomy of the spine as viewed on image report or as envisioned by the physician's description. These included a narrow spinal canal, the nerve being mechanically loaded, or age-related changes in the discs. High confidence in the MRI reports emerged. There were descriptions that the spine had an injury.

"Well *eh* he (surgeon) said that in principle we will do this, screw together these disks and remove material, in principle, and fix it, and that bit you will notice the day after. And *eh* it feels bloody well actually, that it is like that..." (1)

There were descriptions that the back-related symptoms could be influenced by exercise. Other factors that were mentioned were the importance of muscle function for reducing back-related symptoms, and that muscle strength and muscle function could improve loading of the spine. Disc herniation could be reduced by exercises, and gain of general fitness by exercises prior to surgery were also reported.

"Well, if I strengthen the muscles in my back so I get stronger there, it will be more resistant against my problem, that it gets pinched and things like that. I'm absolutely convinced that this is correct, because I've had less problems, not so often, compared to before I started doing exercises. So that is a good explanation that it is beneficial." (2)

"My thought is that the recovery process will take longer if I just lie still and wait for the operation. That is how I see it." (11)

Searching for feelings of trust about the spine was the reason for surgery for some informants, while others stated that the reason was to become pain-free, to be able to do all activities, and not being afraid of relapses.

"Yes, it is good (no symptoms now), just scared to death that it will come back. That's the only thing I'm afraid of, that it will come back. So that's why I want to have surgery. Even though there is a risk with surgery, I'll take that risk. Because 
I don't want to go around being afraid all the time. Yes, I want to be able to walk more and move more safely. So that I can feel confident with my back." (13)

Informants reported challenges in communication with healthcare professionals, relating to their desire to become well-informed about symptoms. Different strategies were described: using informal personal networks to interpret their healthcare records, needing to be stubborn, and demanding a better dialogue with professionals. Lack of knowledge about LBP limited their ability to formulate adequate questions. When they managed to ask questions, however, they received satisfactory answers.

"Sometimes it's hard to know what questions to ask (the symptoms), because I don't have the basic knowledge, but if I know fairly well, then at least I can always get help with the answer, and that's good." (6)

Uncertainty about the clinical justification for surgery, both when the pain had not resolved after a previous surgery and in relation to first-time surgery, was described. Experiences of a lack of explanation about symptoms, which caused doubt and distress, especially concerning leg symptoms, were described.

"It's easier, to live with back pain than the symptoms in my feet and legs, because that is both more annoying and more painful. That is one thing that I feel that I would like to know, if feet and leg pains come from the spine or not, if it is not already known." (3)

Doubt as to whether physiotherapy could influence symptoms, expressing a biomedical explanatory model, also emerged.

"It (pre-surgery physiotherapy) must have done something, because it (the symptoms) are subsiding. How this works physically in the body, I don't know for sure." (7)

\section{Influences on social functioning}

The ability to resume daily routines, an improved ability to work, and greater social activity were reported. Furthermore, daily activities were less demanding and more pleasant. There were also reports that day-to-day life had previously not been limited, so any changes were not expected. Being able to start doing more demanding activities after pre-surgery physiotherapy was also experienced.

"Before I had to sit almost all the time (at work). One day I was so happy, I told my boss that this was the first day in several months that I could stand up the whole time." (17)

"Because I can like *eh* I can make contact with them (grandchildren), be with them in another way now. Physically too. Because I run around with them and they chase me and I can chase them, for short periods, because they don't have to have so much time for that, so, yes. It is really nice." (5) 
The pre-surgery physiotherapy fulfilled the need for interaction with other people in the same situation, while limited social interaction was also reported.

Independent of improvement levels, a desire for a more active life, such as taking walks, running and a greater degree of socializing, were expressed. Longed to be able to resume more demanding activities, such as downhill skiing, orienteering, sailing, walking in the mountains or carrying a backpack on city trips were also reported. These longings were sometimes expressed in terms of longing for a better quality of life.

"And in my daily living, going for walks, in the forest and, yes, in the archipelago and the mountains is what I would like to do. But it stops there. So it affects my quality of life very much." (14)

\section{The ability of the model of care to influence reassurance and prevention} Experiences of pre-surgery physiotherapy led to reflections about the model of care. One reflection was to combine physiotherapy with analgesics prescription or with sick leave when it was expected that it would decrease pain, help people to stay active and maintain a better mood. The experience that pre-surgery physiotherapy decreased pain duration and improved function led to reflections that the model of care be changed, making the pre-surgery physiotherapy available earlier. A demand for a guarantee that one would retain the option of future surgery influenced the decision to decline the planned surgery. A need for clear information about this was expressed.

"Twice I have been offered surgery and I have cancelled. Perhaps partly due to the fact that I have been allowed to stay on the waiting list and get help (=surgery) if I need it." (6)

It was suggested that pre-surgery physiotherapy should be part of the normal preparation for surgery.

"Yes, but in the healthcare sector, they try to encourage you to use physiotherapy, or I don't know how to go about that but, they say: Now 'When you are going to have surgery?' and that means that 'Now you should come here for ten physiotherapy sessions, otherwise you won't get the surgery'. It's like when they say that you need to stop smoking if you're going to get surgery. Isn't it really the same thing? Don't smoke, don't be inactive. *eh* I don't know but it's really important I think. Absolutely." (14) 


\section{DISCUSSION}

There is a knowledge gap concerning the pre-surgery phase in patients with degenerative lumbar spine disorders scheduled for surgery. This period has seldom been studied, and the work presented here adds to knowledge about a physiotherapy intervention, pain sensitivity and patients' experiences of the presurgery phase.

\section{Somatosensory function}

Somatosensory profile measured with QST for the group of patients with degenerative lumbar spine disorders scheduled for surgery were within the normal range compared to reference values. Somatosensory profile, however, was altered in $22 \%$ of patients before spinal surgery, which may indicate disturbed somatosensory function. Most of these patients had loss of somatosensory function. They reported greater pre-surgery pain and poorer mental health component pre-surgery, than the rest of the cohort (paper I). Knowledge about pain biology and pain mechanisms has increased in recent years, and this has led to a recommendation that the analysis of pain mechanisms be used as one important dimension in diagnostics. It is claimed that this will improve decision making about treatment $(47,48,132,136)$. All of the participants of the study population had had a long duration of pain, and half of them had had back and/or leg pain for longer than 2 years pre-surgery (paper I). Such patients run the risk that maladaptive pain responses develop, which makes the analysis of pain mechanisms an important part of pre-surgery screening. Knowledge about whether centrally mediated pain mechanisms are involved contributes to the decisionmaking process about treatment and the need for additional treatment.

To our knowledge this is the first prospective study to show that higher sensitivity to cold and pressure pain in a non-affected body region pre-surgery is associated with lower function, higher pain intensity, and lower self-efficacy postsurgery in patients with LDH 3 months post-surgery (paper II). Interesting is that, the associations at 3 months post-surgery remained for cold pain and for both cold and pressure pain there were also associations with poorer health and more signs of depression in the additional analysis on 1 year post-surgery PROMs data. The association can be interpreted as a sign of widespread pain when a nonsymptomatic body region is affected. A lower PPT in patients having knee or hip replacement is associated with higher pain intensity post-surgery, although it does 
not predict pain relief post-surgery (137). It is expected that the pain mechanism in patients with $\mathrm{LDH}$ is neuropathic, in which pain and altered sensory function occur in the affected area only (48). A study by Puta et al. (138) has shown that patients with CLBP have lower pain thresholds both in the lower back and in the hand, a non-affected body region, than those of healthy controls. They interpreted the difference in somatosensory sensitivity between the two groups as being caused by alterations at higher levels of the neuraxis (138). Increased sensitivity, lowered pain thresholds measured with QST has been described as a sign of an aberrant pain regulation system, and may be a risk factor for poor outcome after surgery (91). The association between QST measurements (cold and pressure pain) and post-surgery outcome is interesting, and we suggest that PPT and CPT in the hand should be studied in more detail, as a sign of widespread pain response presurgery in patients with LDH. The first step in a more thorough investigation of pain mechanisms may be to limit QST to testing pressure and cold pain thresholds. This may avoid unnecessary testing, and save both time and other resources.

The different results in patients with LDH and LSS may be caused by the presence of inflammation in $\mathrm{LDH}$. In $\mathrm{LDH}$, the sciatic pain has not only a neuropathic component, in which mechanical stimuli cause the nerve root compression, but also an inflammatory component (139). Inflammation causes a more on-going nociceptive stimulus and constant pain experience, which may increase the risk of plasticity changes in the nervous system (140).

Questionnaires may be used to determine whether signs of centrally mediated pain are present. The discriminant validity for the mechanism-based pain classifications have been evaluated for patients with CLBP, with or without leg pain (141). The three mechanism-based pain classifications: nociceptive, peripheral neuropathic and central sensitisation, differ in PROMs recorded for pain, general health, back-related disability, depression and anxiety (141). An alternative is to use the Central Sensitization Inventory (CSI) to analyse signs of centrally mediated pain. This instrument is valid for five severity levels, determined as the mean score on the CSI (142). The severity levels can be used in the clinical decision process about intervention and to evaluate responsiveness to treatment (142). The qualitative interviews carried out in this thesis (paper IV) revealed that participants want clearer explanations about symptoms, especially leg symptoms, and clearer reasoning for surgery. This may, at least partly, be achieved by explaining to the patient the pain mechanisms involved. This might be facilitated by the use of a biopsychosocial model, which broadens the biomedical explanation of the diagnosis in the communication with the patient. It is generally recommended when providing healthcare that a broad perspective is used (7), and this improves pain cognition and decreases healthcare consumption when used in pain management $(66,70,71)$. 


\section{Pre-surgery physiotherapy - patient-reported outcome measures}

Pre-surgery physiotherapy including treatment-based classification physiotherapy, a tailor-made exercise programme, and use of a behavioural approach decreased pain and fear-avoidance beliefs, improved the quality of life, and led to increased activity levels pre-surgery (paper III). In contrast, signs of depression increased and self-efficacy decreased during the pre-surgery period in the waiting-list group. The effect sizes were small to moderate for both the improvements and the deteriorations. Improvements in ODI and VAS back and leg pain in the physiotherapy group after the pre-surgery intervention were statistically significant, but lower than the MCIC reported in previous studies $(130,143)$. The MCIC for ODI is 10 units and for VAS back pain 18 units, in patients with CLBP without signs of LDH, LSS or spondylolisthesis treated with surgical or nonsurgical interventions (130). Greater changes are required when only surgery intervention is used in patients with LDH: ODI 20 and EQ-5D 0.30 (144). The improvement in EQ-5D (0.12) in the work reported here is within the range presented in previous studies in patients with CLBP treated with physiotherapy, EQ-5D 0.09-0.28 (143). Differences between studies in the MCIC value depend on the use of different statistical methods and other factors such as differences in patient group, duration of the trial, and nature of intervention used $(130,143)$. Furthermore, the MCIC for deterioration is generally smaller than the MCIC for improvement (130). The broad range in MCIC values caused by these factors supports the use of study-specific MCICs. The improvements in the physiotherapy group were larger in VAS back and leg pain, EQ-VAS, and FABQ-PA than the study-specific MCIC. This shows that these changes are important in this patient group during the time pre-surgery. The result also confirm that it is not harmful to exercise and increase activity level during the time being on the waiting list for surgery.

Both groups improved significantly in all PROMs after surgery, with no differences in neither primary nor secondary outcomes between groups, except for higher activity level at the 1-year follow-up in the physiotherapy group. The presurgery physiotherapy was well-tolerated, but many patients, $43 \%$, did not receive the planned intervention. This was most often due to the surgery being rescheduled to an earlier date.

The principal aim of the surgery is to reduce the neuropathic pain symptoms in LDH and LSS, while that of the pre-surgery physiotherapy, in contrast, aims to target broader aspects of the LBP, based on the biopsychosocial model. In another prehabilitation study that used an education-based intervention, the primary outcomes for pain and function did not improve, but patients used less healthcare 
at the 1-year follow-up. The authors suggested that the effect was related to a change in behaviour towards more self-management (66). This effect was sustained at the 3 -year follow-up $(66,70)$. The work reported here does not include analyses of healthcare use nor recurrence rate, but the 2-year follow-up will reveal whether the higher activity level is associated with fewer recurrences. In a study of a similar population by Delitto et al. have compared surgery and physiotherapy in patients with LSS who were candidates for surgery (59). Physical function according to SF-36 during in a 2-year period was the same for all patients, independently of whether they had surgery, surgery with physiotherapy, or physiotherapy alone. Irrespective of the potential effect mechanism of the intervention, the results were similar. The authors points out the importance of shared decision making awaiting further research results (59).

The pre-surgery physiotherapy reduced fear of movement, and exercises can empower the patient to be more active and return to everyday activities. The waiting list group had deterioration in depression score and self-efficacy (paper III). So even if the differences are small, the combined improvements in the presurgery physiotherapy group and the deterioration in the waiting-list group confirm that psychological effects have occurred. FABQ-PA was not evaluated in the four previously published studies of prehabilitation (66-69). The period spent on the waiting list for spinal surgery is $2-5$ months in Sweden, and it is crucial to avoid deterioration, reduce fear, and support activity during this period. Signs of depression is a predictor for lower function and higher dissatisfaction after surgery for spinal stenosis $(145,146)$ and a high FABQ-PA is a predictor for a poorer outcome after surgery for LDH and LSS (147). The levels of FABQ-PA in paper III were higher than in a previous study of patients with acute and persistent LBP (148). They were, however, the same as in patients with LSS with a mean age of 75 years, where a FABQ-PA greater than 16 was considered to be high (149). The findings presented in this thesis show that fear-avoidance beliefs, depression, and self-efficacy are areas that should be targeted in pre-surgery interventions.

Other studies apart from studies on pre-surgery have shown promising effects on psychosocial dimensions as well as fear avoidance. Patients with DDD who carried out exercise had lower levels of FABQ-PA at the 1-year follow-up than patients who underwent spinal surgery (150). Further, the psychosocial dimension of PROMs improved in a prospective cohort study of 41 patients with LDH on the waiting list for surgery, after a structured physiotherapy intervention that included mechanical diagnosis and therapy (MDT) and motor-control exercises (151). The patients improved in: kinesiophobia (fear of pain measured by the Tampa scale for kinesiophobia), health-related quality of life, depression and self-efficacy postsurgery. Further, function and pain were better at the 3-month and 2-year followups (136). 
A pre-surgery intervention may reduce the risk of deconditioning, which may, in turn, have post-surgery effects on long-term pain, function and health. It might be more effective to introduce the intervention earlier and in this way target a broader LBP population, since exercise and education can influence fear of movement, attitudes and beliefs about the condition $(66,70,151)$. Exercise has positive effects over the complete life span, and pain due to a musculoskeletal disorder may reduce the possibility to be active. This is the case for people with LSS, who exercise regularly less commonly than those without LSS $(\mathrm{P}<0.001)$ (40). Physiological results are consistent with these findings, and people with LSS have greater impairments in trunk endurance, leg strength, leg strength asymmetry, and knee and ankle ROM than people without LSS (152). This is useful information when constructing an exercise or rehabilitation programme.

Ideas about treating knee and hip osteoarthritis changed many years ago (153), and physiotherapy with exercise is standard in these conditions before making a decision about surgery. LBP is a more diverse range of conditions than osteoarthritis, but we suggest that all patients who do not need acute surgery should have the opportunity to exhaust non-surgical interventions, which should include individually tailored interventions, before a decision about surgery is taken, as recommended in the guidelines $(8,9,20,51,53)$.

\section{Pre-surgery physiotherapy - patients' experiences}

The interviews with patients who had had at least 12 physiotherapy visits adds new knowledge about patients' experiences in the pre-surgery phase in addition to the quantitative findings.

\section{Experiences of how symptoms are explained}

It emerged that the informants mostly use biomedical explanations for their symptoms, referring to image report and describing injuries to the lumbar spine. Similar findings have been shown in a qualitative interview study in patients with shoulder pain, who mainly use a biomedical explanation for impingement (154). The explanations are well-suited to understanding the surgical intervention, but are not optimal when discussing non-surgical interventions such as physiotherapy. In the work presented here, we show that those who use a broader explanation and who add that exercise and posture changes can influence the symptoms are more confident that physiotherapy and self-management can be successful. A broader explanatory model that includes biopsychosocial aspects of pain, with NE (155), muscle function and the efficacy of self-care strategies seems to be more suitable 
for patients who are undergoing pre-surgery physiotherapy and post-surgery rehabilitation.

The categories "Strategies to become well-informed" and "Uncertainty how intervention can influence symptoms", showed that individualised information is requested and lack of information causes anxiety. Given that anxiety may have a negative effect on pain $(45,47)$, and in this way on post-surgery outcome, the study by Kesanen et al was conducted (68). The group who received a feedback session to make it possible to clarify the information about surgery had lower pre-surgery anxiety than the control group, who did not (68). Although, the post-surgery PROMs did not differ between the groups, so post-surgery follow-up was suggested (68).

In the qualitative study one point of view was that informants expected that surgery was a guarantee for no relapse. Another point of view expressed was that surgery would enable them to trust their own spine again when taking part in any activity. However, the recurrence rate of LBP in LDH is $15-20 \%$ and the re-surgery rate for $\mathrm{LDH}$ of the same level is 6\% (61) within 2 years. It is clear that some informants have unreasonable expectations, and would need information and a discussion to promote realistic expectations, since higher pre-surgery expectations lead to poor post-surgery satisfaction. The re-surgery rate for patients who have had one previous surgery for LSS is $11 \%$ during 4 years, and it is $17 \%$ in those who have had more than one (156). Zaina et al. (157) recommend communication about expectations and treatment alternatives.

\section{Patients' experiences of the influences on back-related health after pre- surgery physiotherapy}

Some findings in the interview study support the findings of the PREPARE study, which is described in paper III. Both studies illustrates patient-reported effects occur in several dimensions of the biopsychosocial model. In the interview study it emerged that even if symptoms did not improve, participants experienced feeling better doing exercises than being inactive and that it reduced feeling depressed. This suggests that having the experience that exercise supports psychological health, or the experience of an improvement in symptoms, can make it easier to cope with LBP symptoms. The findings are compatible with evidence that exercise has a positive effect on depression (82).

The qualitative study showed experiences of reduced feeling of fear in daily activities after pre-surgery physiotherapy, which is compatible with the results from paper III. In the latter case, the levels of FABQ-PA were lower in the physiotherapy group after pre-surgery physiotherapy than they were in the control group. It has been proposed that fear avoidance affects both disability and work loss (111), and that a higher level of fear avoidance in physical activity (FABQ- 
PA) is associated with a poorer outcome of spinal surgery (147). A qualitative study of patients who had undergone either surgery or physiotherapy for LDH showed that patients who had received physiotherapy more often made statements about "feeling of well-being" (158). We suggest that reducing fear avoidance should be considered when developing pre-surgery physiotherapy. Pre-surgery physiotherapy seems to encourage patients to reflect about changes in lifestyle, and this is a component that should be emphasised in the development of presurgery physiotherapy.

It was interesting to discover that the pre-surgery physiotherapy was experienced as a time to understand and reflect about interventions for LBP. In another qualitative study, patients undergoing non-surgical intervention for spinal stenosis required advice on lifestyle changes (159). Some patients experienced that the improvements led to confidence in the intervention, and decided to extend the timeframe for exercising before making a final decision about surgery. Other reflections about the model of care suggested that access to the structured physiotherapy programme be given at an earlier stage, which is compatible with the recommendations made in the guidelines that non-surgical interventions be exhausted before taking a decision about surgery $(8,20,51,53)$. Informants suggested that physiotherapy should be required pre-surgery, in the same way that it is currently required that patients are non-smokers. The clinical routine that allows patients to return to the spinal clinic within 6 months without a new referral gives patients the confidence required to postpone the decision about surgery.

The findings from the interview study provide insight into patients' experiences, and are useful in the development of pre-surgery physiotherapy. It may be possible to transfer the results into the development of pre-surgery physiotherapy for other patient groups. Furthermore, it may also be possible to transfer the findings into the development of parts of the model of care for the patient group.

\section{Methodological considerations}

One limitation in paper I was, in the QST protocol used in this study tests for cold, $\mathrm{CPT}$, stopped at $+10^{\circ}$, while the CPT test used in the reference data stopped at $0^{\circ}$, indicating a risk for underestimation rather than overestimation of the results. When CPT in reference data had the broad normal range $32-0^{\circ} \mathrm{C}$ in most age groups $(128,129)$, that difference in degrees at end-points had minor influence on the result.

The work presented in paper II analysed pain sensitivity and not detection sensitivity. PPT is the most sensitive QST measurement for pain excitability in patients with osteoarthritis (160), and in CLBP (161). Further, there is moderate 
evidence that CPT is a predictor for outcome with respect to pain and disability in patients with WAD (162). Also, we limited somatosensory function description to only reporting QST data from the hand. We recommend that a selection of QST measurements be applied, chosen to suit the research question. A non-effected body region should be selected when analyzing signs of centrally mediated pain.

The results presented in paper II should be interpreted with some caution, since the number of patients is low. It would be possible to use more independent variables in a larger cohort, and it would be possible, for example, to adjust for psychological variables, which has been shown to modify the outcome of the QST (101). Furthermore, the predictive value of cold and pressure pain sensitivity in hand is of interest to support the clinical reasoning process for choice of treatment. The small number of patients also brings into doubt how general the results are. This is, however, alleviated to a certain extent since the profile of PROMs was similar to that of the population in the Swedish spine register (15). We conclude that the results are general, and valid for a larger population within the same healthcare system.

In the work presented in paper III, patients with degenerative lumbar spine disorders scheduled for surgery were included. The most common reason for lumbar surgery is radiculopathy based on symptom classification and corresponding findings in image report. This introduced a heterogeneity related to the diagnostic groups LDH, LSS, spondylolisthesis and DDD. However, patients were included in the study on the basis of the severity of symptoms, and it is not primarily our aim to classify them into subgroups according to the ICD-10 classification. One drawback was that more patients with radiculopathy related to LDH were lost to the study due to early surgery.

The low number of participants who achieved the optimal level of adherence, at least 12 visits, challenges the conclusions drawn from the pre-surgery physiotherapy (paper III). The decision to define 12 physiotherapy sessions as the level of optimal adherence was taken since 12 sessions exceeding $50 \%$ were suggested to ensure improvement in physical function. It is harder to determine the level of adherence required to achieve improvement in other dimensions. Improvements in FABQ-PA at the 1-year follow-up can be achieved with three daily exercise sessions for three weeks $(148,150)$, and FABQ-PA at the 3-month follow-up can improve after an exercise intervention twice per week for nine weeks (151). The pre-surgery interventions in the existing prehabilitation studies has varied between one education session $(66,68)$ and a combined intervention with 30 minutes of daily exercise for 6-8 weeks with post-surgery rehabilitation for 30 minutes twice daily during hospital stay (67). The behavioural approach in the pre-surgery physiotherapy intervention was designed to be used in a pragmatic way from the patients' questions, needs and their reported activity limitations in 
PSFS. Because physiotherapy in the pre-surgery period is a new intervention, it might have been more efficient with an education package, such as NE intervention (66), instead of our pragmatic approach.

One limitation of the qualitative interview study (paper IV) was that the informants knew that the interviewer was physiotherapist in the research group, which may have affected their replies. This might give a risk for that social desirability may have affected their replies. However, the interviewer had not treated the patients in the PREPARE study, which lowers the risk of this. On the other hand the interviewer had long experiences of treatment of low back patients and a good understanding of the clinical encounter and the patients. The participants were offered the opportunity to choose the location of the interview, to allow them to choose an environment that they experienced as neutral and comfortable. All participants, however, chose to conduct the interview at the hospital in conjunction with a hospital visit.

It was our aim that the study population be varied, in order to provide a diversity in experiences of the phenomenon and support credibility (93). So the parameters age, gender, and distance to the physiotherapy clinic were monitored during inclusion, and in this way ensured that the variety was sufficient.

To contribute to the trustworthiness in the data collection (93), patients who had attended at least 12 visits were selected, to ensure that those interviewed had sufficient experience of the phenomenon, pre-surgery physiotherapy intervention. Some information will, of course, not be collected when this selection method is used. It is not possible, for example, to analyse the reasons that patients decided not to continue the intervention as planned. Further, about the phenomenon studied, the data content from the interviews was extensive, and the study presented in paper $I V$ focussed on the informants' experiences of how symptoms are explained and influences on back-related health after pre-surgery physiotherapy. It is planned to use the remaining data for an analysis of the experiences of performing the pre-surgery physiotherapy intervention. When designing the interview guide, we planned to use conventional content analysis. This is recommended when a greater understanding of a phenomenon is desired and previous research is limited (135). This was the case for pre-surgery physiotherapy. We thus used inductive content analysis to derive codes from the data. It subsequently became clear, however, that the subcategories could be organised with inspiration from the biopsychosocial model (7), which showed that influences on back-related health arose in all dimensions of the biopsychosocial model. In this model of health, the category "The ability of the model of care to influence reassurance and prevention" becomes an additional component, although it did not fit into the various dimensions of the model. 
One drawback, very common in research carried out in Sweden, is that one of the inclusion criteria is fluency in Swedish, which is a drawback in terms of generalisability. 


\section{CLINICAL IMPLICATIONS}

More than one third of the patients had low or very low activity level and only 58\% had had at least one physiotherapy visit the 12 months before decision about surgery. It can be suggested that non-surgical intervention might have better possibilities for improvements in an earlier stage when patients are less deconditioned. One clinical implication is to provide and exhaust non-surgical interventions before decision about surgery, as recommended by clinical guidelines $(8,9,20,51,53)$.

The associations between pain sensitivity and poorer function, pain, self-efficacy, depression score and health is promising as a screening tool for wide spread pain to address possible need of additional intervention in conjunction to the intervention for the degenerative lumbar spine disorders. By measuring only cold and pressure pain in a single body region it is feasible to do in clinical routine. However, the value of cold pain and pressure pain sensitivity for screening of widespread altered pain response pre-surgery need analysis in larger study group before clinical use.

Pre-surgery interventions in degenerative lumbar spine disorders have only been evaluated in few studies, and with the lack of broad post-surgery results from our study, we do not have any clear recommendations. Our studies indicate that improved information and explanations about symptoms and interventions are wanted and that the fear in physical activity and psychological factors seem to be of importance in further development of pre-surgery physiotherapy.

Symptoms were described mainly by a biomedical explanatory model based on image report. Those using a broader explanatory model described confidence to physiotherapy and self-management to influence their back-related symptoms. This suggests that more emphasis on explanatory models suitable for surgery, and for pre-surgery physiotherapy, post-surgery physiotherapy, and self-care is needed in the professionals' dialogue with patients. 


\section{CONCLUSIONS}

More than half of the participants had had back or leg pain for more than 2 years. The somatosensory profile for detection and pain thresholds were within normal range compared to reference values, for the group of patients with degenerative lumbar spine disorders scheduled for surgery. On an individual level, 22\% of patients had an altered somatosensory profile before spinal surgery, which may indicate disturbed somatosensory function. Such patients reported more pain and worse mental health than the rest of the cohort.

Being more sensitive to pressure and cold pain in the hand, as a sign of widespread pain pre-surgery, was associated with worse function, pain and selfefficacy 3 months post-surgery in patients with disc herniation. At 1 year postsurgery, these associations' remains for cold pain and for both pressure and cold pain there were also associations with poorer health and more signs of depression.

Pre-surgery physiotherapy that included treatment-based classification physiotherapy, a tailor-made exercise programme, and use of a behavioural approach decreased pain and fear-avoidance beliefs, improved quality of life, and increased activity level. Signs of depression increased and self-efficacy decreased in those who only waited for surgery. The improvements were small. Both groups improved significantly after surgery with no differences in neither primary- nor secondary outcomes between groups, except for a higher activity level in the physiotherapy group at 1-year follow-up. The pre-surgery physiotherapy was well tolerated, but many, $43 \%$, did not complete the planned intervention. The most common reason for this was that surgery had been rescheduled to an earlier date.

More than one third reported very low or low activity level and only 58\% of those included in the PREPARE study had visited a physiotherapist at least once the 1 year preceding the decision to undergo surgery.

Symptoms were described mainly by a biomedical explanatory model based on image report. Those using a broader explanatory model described confidence to physiotherapy and self-management to influence their back-related symptoms. It emerged that patients desired clearer reasoning about symptoms and treatments.

Experiences that pre-surgery physiotherapy had influences on symptoms, physical function, coping, well-being and social functioning to various degrees emerged. Those whose symptoms did not improve, experienced feeling better performing exercises than being inactive and exercises improved their frame of mind. Pre-surgery physiotherapy as part of a model of care was described as a tool 
for reassurance through education and exercise, and provides time to reflect on interventions and lifestyle changes. This can inform the development and implementation of care for this patient group. 


\section{FUTURE RESEARCH}

The finding in this thesis that lower pain sensitivity in a non-affected body region was associated with poorer post-surgery outcome in patients with LDH is of interest to study further. We are continuing to collect patients and with a larger number of patients, multivariate analysis can be done to find out if it is a screening tool potentially capable of identifying patients with suboptimal functional outcome, e.g., ODI.

In the development of pre-surgery physiotherapy intervention one area to put emphasis on is a more individually based approach, since the interview study showed that there is a wide range in their longings for an active life. Another area is fear avoidance in physical activities, when both the result that FABQ-PA decreased and that patients' experiences of being less afraid in physical activities after pre-surgery physiotherapy is of interest to study further.

It would be interesting to study the additive value of the neuroscience education to the pre-surgery physiotherapy model.

In the PREPARE study the PROMs at the 2-year follow-up will be analysed to see if the higher activity level in the pre-surgery physiotherapy group is maintained and if it has influenced the recurrence rate and use of health care.

Further analysis of the interview study about patients' experiences of performing the pre-surgery physiotherapy and about exercises in a later stage. This together with the findings about patients experiences presented in the thesis will be helpful in the development of the pre-surgery physiotherapy intervention. 


\section{SUMMARY IN SWEDISH}

Bakgrund: Patienter på väntelista för ryggoperation har ofta haft smärta under lång tid, vilket kan ge påverkan på smärtregleringssystemet, fysisk funktion och hälsa, med risk för negativ inverkan på resultatet efter kirurgi. Prehabilitering kan ha fördelaktiga effekter efter operationen, genom förbättring av funktion före operation.

Syfte: Det övergripande syftet med avhandlingen var att studera fysioterapi och somatosensorisk funktion före operation hos patienter med degenerativa ländryggs åkommor och utforska patienternas erfarenheter av pre-operativ fysioterapi.

Metoder: Somatosensorisk funktion mättes med kvantitativ sensorisk testning (QST). Pre-operativ fysioterapi utvärderades med självrapporterade resultatmått (n = 197). Patienternas erfarenheter av hur ryggrelaterade symtom förklaras och påverkan på ryggrelaterad hälsa efter pre-operativ fysioterapi undersöktes.

Resultat: Hälften av patienterna rapporterade att de hade haft rygg eller bensmärta i mer än 2 år. På gruppnivå var den somatosensoriska profilen inom rapporterade referensvärden. På en individ nivå fanns en förändrad somatosensorisk profil hos 23/105 patienter, dessa var äldre, oftare kvinnor och rapporterade högre smärta, större smärtutredning och sämre SF-36 MCS (mental hälsa).

Patienter med diskbråck, som var mer känsliga för trycksmärta $i$ handen före operation, var associerade med sämre funktion, tilltro till egen förmåga, fler tecken på ångest och depression före operationen, sämre funktion, tilltro till egen förmåga och bensmärta 3 månader efter operation samt sämre hälsorelaterad livskvalitet, tilltro till egen förmåga, fler tecken på depression 1 år efter operation. Resultaten för känslighet för köld smärta var liknande, förutom att det även var förknippat med sämre funktion, rygg och bensmärta 1 år efter operation.

Fysioterapi gruppen hade efter pre-operativ intervention mindre ryggsmärta, bättre funktion, hälsa, tilltro till egen förmåga och fysisk aktivitetsnivå, mindre rörelserädsla och färre tecken på depression och jämfört med väntelistegruppen. Effekterna var små. Båda grupperna förbättrades signifikant efter operationen, utan skillnader mellan grupper, förutom att den högre fysiska aktivitetsnivån i fysioterapi gruppen kvarstod vid 1 årsuppföljningen. Bara 58\% av patienterna rapporterade att de hade haft minst ett besök för rehabilitering året innan beslut om operation.

Patienter upplevde i varierande grad att fysioterapi före operation hade påverkat symptom, funktion, coping, välbefinnande och social funktion. Pre-operativ fysioterapi upplevdes som ett verktyg för att skapa trygghet och ge möjlighet till 
reflektion över behandling och livsstil. Patienterna använde i huvudsak biomedicinska förklaringsmodeller baserat på bilddiagnostik för att förklara sina ryggrelaterade symtom. Både bredare och mer avgränsande, såväl som brist på förklaringar till symptom framkom. Det fanns en önskan om att vara välinformerade om sina symptom och behandling.

Slutsatser: Mer känslighet för tryck- och köldsmärta i handen, som ett tecken på utbredd smärta före operationen, var associerad med sämre funktion, smärta och hälsa efter operation hos patienter med diskbråck.

Pre-operativ fysioterapi gav minskad smärta, minskad rörelserädsla, förbättrad hälsorelaterad livskvalitet och minskade risken för försämring av psykologiskt välbefinnande före operation. Förbättringarna var små och förbättringar efter operationen var lika för båda grupperna. Vid 1 årsuppföljning hade fysioterapigruppen fortfarande en högre fysisk aktivitetsnivå jämfört med väntelistegruppen. Pre-operativ fysioterapi tolererades väl och gav inga komplikationer. Patienter upplevde att fysioterapi före kirurgi skapade trygghet och möjlighet att reflektera över behandlingar och livsstil. Symtom beskrevs huvudsakligen i linje med en biomedicinsk förklaringsmodell. De som använde en bredare förklaring, hade tilltro till fysioterapi och att egenbehandling kan påverka deras ryggsymtom. 


\section{ACKNOWLEDGEMENTS}

I would like to thank everyone that have been supporting me in various ways during my $\mathrm{PhD}$ journey. A special thanks to:

My main supervisor Birgitta Öberg, who took me on, knowing that I like to learn more about patients with back pain and stayed beside me throughout this journey. Thank you for sharing your knowledge!

My co-supervisor Paul Enthoven, for interesting conversations and all your help in science, writing and SPSS.

My co-supervisor Hans Tropp, for sharing your expertise as a spinal surgeon, often in quick short answers packed with knowledge.

Co-author Björn Gerdle, for contributing to our QST-study. Thanks for sharing knowledge, constructive feedbacks, and sometimes with wonderful comments such as; "You need to inform the reader here, you are not writing a thriller..."

Co-author Allan Abbott, for all your help in science and writing.

Henrik Hedevik, for your energy, statistical support and interest in our studies.

All my colleagues at the Division of Physiotherapy and the administrators, thanks for help, inspiring discussions, laughs and encouragements! It has been rewarding to be part of the doctoral group at the Division of Physiotherapy, thanks!

The Orthopaedic clinic, the spinal surgeons for collaborating and help with recruiting patients for the study. The surgeon planers (Tina and Pia), all nurses and healthcare administrators thanks for your help when I had patients at your clinic.

All colleagues at the Rehab enheten at the Orthopaedic clinic, for warm welcomes. Special thanks to Teresa Holmgren and Gustav Ljunggren for collaborating with our ongoing study. Thanks Maria Öberg for your work in the PREPARE and the QST study. Britta Toresson, thanks for your help.

All physiotherapists at the Rehab Öst, Rehab Väst, Aktiva Rehab, Rörelse\&Hälsa, for our collaboration and treating the PREPARE study patients.

Special thanks to all the patients who took part in this research, it is from you we are learning.

Colleagues at my prior work place Rörelse\&Hälsa, thanks for many interesting and fun years together with you!

Jan Erik, my husband for all love and support, all the fun things we do keep me energised! As I write this last page of my thesis, you sent me a video. A video of you and two of our daughters out on the lake wake boarding, make me smile. Klara, Camilla and Tyra our wonderful daughters it is so fun spending time with you! Love you all!

Parents Anders and Karin, for always being there, supporting and loving!

Relatives and friends! Back to normal life the 22 of September 
The thesis was supported by the Swedish Research Council, the Faculty of Medicine and Health Sciences", Linköping University and the County Council in Östergötland, Sweden. Their contributions are gratefully acknowledged 


\section{REFERENCES}

1. Hoy D, March L, Brooks P, Blyth F, Woolf A, Bain C, et al. The global burden of low back pain: estimates from the Global Burden of Disease 2010 study. Annals of the rheumatic diseases. 2014;73(6):968-74.

2. Clark S, Horton R. Low back pain: a major global challenge. Lancet (London, England). 2018.

3. Balague F, Mannion AF, Pellise F, Cedraschi C. Non-specific low back pain. Lancet. 2012;379(9814):482-91.

4. da Silva T, Mills K, Brown BT, Herbert RD, Maher CG, Hancock MJ. Risk of Recurrence of Low Back Pain: A Systematic Review. The Journal of orthopaedic and sports physical therapy. 2017;47(5):305-13.

5. Deyo RA, Dworkin SF, Amtmann D, Andersson G, Borenstein D, Carragee E, et al. Focus article: report of the NIH Task Force on Research Standards for Chronic Low Back Pain. Eur Spine J. 2014;23(10):2028-45.

6. Borrell-Carrio F, Suchman AL, Epstein RM. The biopsychosocial model 25 years later: principles, practice, and scientific inquiry. Annals of family medicine. 2004;2(6):576-82.

7. Engel GL. The need for a new medical model: a challenge for biomedicine. Science (New York, NY). 1977;196(4286):129-36.

8. Koes BW, van Tulder M, Lin CW, Macedo LG, McAuley J, Maher C. An updated overview of clinical guidelines for the management of non-specific low back pain in primary care. European spine journal : official publication of the European Spine Society, the European Spinal Deformity Society, and the European Section of the Cervical Spine Research Society. 2010;19(12):2075-94.

9. National Guideline C. National Institute for Health and Care Excellence: Clinical Guidelines. Low Back Pain and Sciatica in Over 16s: Assessment and Management. London: National Institute for Health and Care Excellence (UK) Copyright (c) NICE, 2016.; 2016.

10. Qaseem A, Wilt TJ, McLean RM, Forciea MA. Noninvasive Treatments for Acute, Subacute, and Chronic Low Back Pain: A Clinical Practice Guideline From the American College of Physicians. Annals of internal medicine. 2017;166(7):514-30.

11. Toward Optimized Practice (TOP) Low Back Pain Working Group.

Evidence-informed primary care management of low back pain: clinical practice guideline. Edmonton, AB: Toward Optimized Practice; 2015 : [2018-08-12]. Available from: http://www.topalbertadoctors.org/cpgs/885801

12. O'Connell NE, Cook CE, Wand BM, Ward SP. Clinical guidelines for low back pain: A critical review of consensus and inconsistencies across three major guidelines. Best Pract Res Clin Rheumatol. 2016;30(6):968-80. 
13. Konstantinou K, Dunn KM. Sciatica: review of epidemiological studies and prevalence estimates. Spine. 2008;33(22):2464-72.

14. Konstantinou K, Hider SL, Jordan JL, Lewis M, Dunn KM, Hay EM. The impact of low back-related leg pain on outcomes as compared with low back pain alone: a systematic review of the literature. The Clinical journal of pain. 2013;29(7):644-54.

15. Stromqvist B, Fritzell P, Hagg O, Jonsson B, Sanden B. Swespine: the Swedish spine register : the 2012 report. European spine journal : official publication of the European Spine Society, the European Spinal Deformity Society, and the European Section of the Cervical Spine Research Society. 2013;22(4):953-74.

16. Meyerding HW. Spondylolisthesis; surgical fusion of lumbosacral portion of spinal column and interarticular facets; use of autogenous bone grafts for relief of disabling backache. The Journal of the International College of Surgeons. 1956;26(5 Part 1):566-91.

17. Brinjikji W, Luetmer PH, Comstock B, Bresnahan BW, Chen LE, Deyo RA, et al. Systematic literature review of imaging features of spinal degeneration in asymptomatic populations. AJNR Am J Neuroradiol. 2015;36(4):811-6.

18. Cassidy RC, Shaffer WO, Johnson DL. Spondylolysis and spondylolisthesis in the athlete. Orthopedics. 2005;28(11):1331-3.

19. Herman MJ, Pizzutillo PD, Cavalier R. Spondylolysis and spondylolisthesis in the child and adolescent athlete. The Orthopedic clinics of North America. 2003;34(3):461-7, vii.

20. Kreiner DS, Hwang SW, Easa JE, Resnick DK, Baisden JL, Bess S, et al. An evidence-based clinical guideline for the diagnosis and treatment of lumbar disc herniation with radiculopathy. The spine journal : official journal of the North American Spine Society. 2014;14(1):180-91.

21. Gibson JN, Waddell G. Surgical interventions for lumbar disc prolapse: updated Cochrane Review. Spine. 2007;32(16):1735-47.

22. Vroomen PC, de Krom MC, Knottnerus JA. Predicting the outcome of sciatica at short-term follow-up. The British journal of general practice : the journal of the Royal College of General Practitioners. 2002;52(475):119-23.

23. Carragee EJ, Kim DH. A prospective analysis of magnetic resonance imaging findings in patients with sciatica and lumbar disc herniation. Correlation of outcomes with disc fragment and canal morphology. Spine. 1997;22(14):1650-60.

24. Delauche-Cavallier MC, Budet C, Laredo JD, Debie B, Wybier M, Dorfmann H, et al. Lumbar disc herniation. Computed tomography scan changes after conservative treatment of nerve root compression. Spine. 1992;17(8):927-33.

25. Boos N, Rieder R, Schade V, Spratt KF, Semmer N, Aebi M. 1995 Volvo Award in clinical sciences. The diagnostic accuracy of magnetic resonance imaging, work perception, and psychosocial factors in identifying symptomatic disc herniations. Spine. 1995;20(24):2613-25. 
26. Deyo RA. Treatment of lumbar spinal stenosis: a balancing act. Spine J. 2010;10(7):625-7.

27. Yabuki S, Fukumori N, Takegami M, Onishi Y, Otani K, Sekiguchi M, et al. Prevalence of lumbar spinal stenosis, using the diagnostic support tool, and correlated factors in Japan: a population-based study. Journal of orthopaedic science : official journal of the Japanese Orthopaedic Association. 2013;18(6):893-900.

28. Kalichman L, Cole R, Kim DH, Li L, Suri P, Guermazi A, et al. Spinal stenosis prevalence and association with symptoms: the Framingham Study. The spine journal : official journal of the North American Spine Society. 2009;9(7):545-50.

29. Haskins R, Osmotherly PG, Rivett DA. Diagnostic clinical prediction rules for specific subtypes of low back pain: a systematic review. The Journal of orthopaedic and sports physical therapy. 2015;45(2):61-76, a1-4.

30. Tomkins-Lane C, Melloh M, Lurie J, Smuck M, Battie MC, Freeman B, et al. ISSLS Prize Winner: Consensus on the Clinical Diagnosis of Lumbar Spinal Stenosis: Results of an International Delphi Study. Spine. 2016;41(15):1239-46.

31. Jensen MC, Kelly AP, Brant-Zawadzki MN. MRI of degenerative disease of the lumbar spine. Magnetic resonance quarterly. 1994;10(3):173-90.

32. Winter CC, Brandes M, Muller C, Schubert T, Ringling M, Hillmann A, et al. Walking ability during daily life in patients with osteoarthritis of the knee or the hip and lumbar spinal stenosis: a cross sectional study. BMC musculoskeletal disorders. 2010;11:233.

33. Otani K, Kikuchi S, Yabuki S, Igarashi T, Nikaido T, Watanabe K, et al. Lumbar spinal stenosis has a negative impact on quality of life compared with other comorbidities: an epidemiological cross-sectional study of 1862 community-dwelling individuals. TheScientificWorldJournal.

2013;2013:590652.

34. Dorow M, Lobner M, Stein J, Konnopka A, Meisel HJ, Gunther L, et al. Risk Factors for Postoperative Pain Intensity in Patients Undergoing Lumbar Disc Surgery: A Systematic Review. PloS one.

2017;12(1):e0170303.

35. McKillop AB, Carroll LJ, Battie MC. Depression as a prognostic factor of lumbar spinal stenosis: a systematic review. The spine journal : official journal of the North American Spine Society. 2014;14(5):837-46.

36. D'Angelo C, Mirijello A, Ferrulli A, Leggio L, Berardi A, Icolaro N, et al. Role of trait anxiety in persistent radicular pain after surgery for lumbar disc herniation: a 1-year longitudinal study. Neurosurgery. 2010;67(2):26571 .

37. den Boer JJ, Oostendorp RA, Beems T, Munneke M, Evers AW. Continued disability and pain after lumbar disc surgery: the role of cognitivebehavioral factors. Pain. 2006;123(1-2):45-52.

38. den Boer JJ, Oostendorp RA, Beems T, Munneke M, Oerlemans M, Evers AW. A systematic review of bio-psychosocial risk factors for an unfavourable outcome after lumbar disc surgery. European spine journal : 
official publication of the European Spine Society, the European Spinal Deformity Society, and the European Section of the Cervical Spine Research Society. 2006;15(5):527-36.

39. Sigmundsson FG, Jonsson B, Stromqvist B. Preoperative pain pattern predicts surgical outcome more than type of surgery in patients with central spinal stenosis without concomitant spondylolisthesis: a register study of 9051 patients. Spine. 2014;39(3):E199-210.

40. Sekiguchi M, Yonemoto K, Kakuma T, Nikaido T, Watanabe K, Kato K, et al. Relationship between lumbar spinal stenosis and psychosocial factors: a multicenter cross-sectional study (DISTO project). European spine journal : official publication of the European Spine Society, the European Spinal Deformity Society, and the European Section of the Cervical Spine Research Society. 2015;24(10):2288-94.

41. Gurung T, Ellard DR, Mistry D, Patel S, Underwood M. Identifying potential moderators for response to treatment in low back pain: A systematic review. Physiotherapy. 2015;101(3):243-51.

42. The International Association for the Study of Pain (IASP Task Force on Taxonomy, 1994). [2018-08-12]. Available from: http://www.iasppain.org/terminology?navItemNumber $=576$

43. Melzack R. Pain and the neuromatrix in the brain. Journal of dental education. 2001;65(12):1378-82.

44. Melzack R, Katz J. Pain. Wiley interdisciplinary reviews Cognitive science. 2013;4(1):1-15.

45. Nijs J, Clark J, Malfliet A, Ickmans K, Voogt L, Don S, et al. In the spine or in the brain? Recent advances in pain neuroscience applied in the intervention for low back pain. Clinical and experimental rheumatology. 2017;35 Suppl 107(5):108-15.

46. Nijs J, Apeldoorn A, Hallegraeff H, Clark J, Smeets R, Malfliet A, et al. Low back pain: guidelines for the clinical classification of predominant neuropathic, nociceptive, or central sensitization pain. Pain physician. 2015;18(3):E333-46.

47. Woolf CJ. Pain: moving from symptom control toward mechanism-specific pharmacologic management. Annals of internal medicine. 2004;140(6):44151.

48. Vardeh D, Mannion RJ, Woolf CJ. Toward a Mechanism-Based Approach to Pain Diagnosis. J Pain. 2016;17(9 Suppl):T50-69.

49. Freynhagen R, Rolke R, Baron R, Tolle TR, Rutjes AK, Schu S, et al. Pseudoradicular and radicular low-back pain--a disease continuum rather than different entities? Answers from quantitative sensory testing. Pain. 2008;135(1-2):65-74.

50. Reddi D, Curran N. Chronic pain after surgery: pathophysiology, risk factors and prevention. Postgrad Med J. 2014;90(1062):222-7; quiz 6.

51. Kreiner DS, Shaffer WO, Baisden JL, Gilbert TJ, Summers JT, Toton JF, et al. An evidence-based clinical guideline for the diagnosis and treatment of degenerative lumbar spinal stenosis (update). The spine journal : official journal of the North American Spine Society. 2013;13(7):734-43. 
52. ECRI Health Technology Assessment Group. Treatment of degenerative lumbar spinal stenosis. Evidence report/technology assessment (Summary). 2001(32):1-5.

53. Watters WC, 3rd, Bono CM, Gilbert TJ, Kreiner DS, Mazanec DJ, Shaffer WO, et al. An evidence-based clinical guideline for the diagnosis and treatment of degenerative lumbar spondylolisthesis. The spine journal : official journal of the North American Spine Society. 2009;9(7):609-14.

54. Rasouli MR, Rahimi-Movaghar V, Shokraneh F, Moradi-Lakeh M, Chou R. Minimally invasive discectomy versus microdiscectomy/open discectomy for symptomatic lumbar disc herniation. The Cochrane database of systematic reviews. 2014(9):Cd010328.

55. Forsth P, Olafsson G, Carlsson T, Frost A, Borgstrom F, Fritzell P, et al. A Randomized, Controlled Trial of Fusion Surgery for Lumbar Spinal Stenosis. The New England journal of medicine. 2016;374(15):1413-23.

56. Machado GC, Ferreira PH, Yoo RI, Harris IA, Pinheiro MB, Koes BW, et al. Surgical options for lumbar spinal stenosis. The Cochrane database of systematic reviews. 2016;11:Cd012421.

57. Fernandez M, Ferreira ML, Refshauge KM, Hartvigsen J, Silva IR, Maher $\mathrm{CG}$, et al. Surgery or physical activity in the management of sciatica: a systematic review and meta-analysis. European spine journal : official publication of the European Spine Society, the European Spinal Deformity Society, and the European Section of the Cervical Spine Research Society. 2016;25(11):3495-512.

58. Jacobs WC, Rubinstein SM, Koes B, van Tulder MW, Peul WC. Evidence for surgery in degenerative lumbar spine disorders. Best practice \& research Clinical rheumatology. 2013;27(5):673-84.

59. Delitto A, Piva SR, Moore CG, Fritz JM, Wisniewski SR, Josbeno DA, et al. Surgery versus nonsurgical treatment of lumbar spinal stenosis: a randomized trial. Annals of internal medicine. 2015;162(7):465-73.

60. Ambrossi GL, McGirt MJ, Sciubba DM, Witham TF, Wolinsky JP, Gokaslan ZL, et al. Recurrent lumbar disc herniation after single-level lumbar discectomy: incidence and health care cost analysis. Neurosurgery. 2009;65(3):574-8; discussion 8.

61. Parker SL, Mendenhall SK, Godil SS, Sivasubramanian P, Cahill K, Ziewacz J, et al. Incidence of Low Back Pain After Lumbar Discectomy for Herniated Disc and Its Effect on Patient-reported Outcomes. Clinical orthopaedics and related research. 2015;473(6):1988-99.

62. Fritzell P, Knutsson B, Sanden B, Stromqvist B, Hagg O. Recurrent Versus Primary Lumbar Disc Herniation Surgery: Patient-reported Outcomes in the Swedish Spine Register Swespine. Clinical orthopaedics and related research. 2015;473(6):1978-84.

63. Buser Z, Ortega B, D'Oro A, Pannell W, Cohen JR, Wang J, et al. Spine Degenerative Conditions and Their Treatments: National Trends in the United States of America. Global spine journal. 2018;8(1):57-67. 
64. Carli F, Zavorsky GS. Optimizing functional exercise capacity in the elderly surgical population. Current opinion in clinical nutrition and metabolic care. 2005;8(1):23-32.

65. Santa Mina D, Clarke H, Ritvo P, Leung YW, Matthew AG, Katz J, et al. Effect of total-body prehabilitation on postoperative outcomes: a systematic review and meta-analysis. Physiotherapy. 2014;100(3):196-207.

66. Louw A, Diener I, Landers MR, Puentedura EJ. Preoperative pain neuroscience education for lumbar radiculopathy: a multicenter randomized controlled trial with 1-year follow-up. Spine. 2014;39(18):1449-57.

67. Nielsen PR, Jorgensen LD, Dahl B, Pedersen T, Tonnesen H. Prehabilitation and early rehabilitation after spinal surgery: randomized clinical trial. Clinical rehabilitation. 2010;24(2):137-48.

68. Kesanen J, Leino-Kilpi H, Lund T, Montin L, Puukka P, Valkeapaa K. Increased preoperative knowledge reduces surgery-related anxiety: a randomised clinical trial in 100 spinal stenosis patients. European spine journal : official publication of the European Spine Society, the European Spinal Deformity Society, and the European Section of the Cervical Spine Research Society. 2017;26(10):2520-8.

69. Rolving N, Nielsen CV, Christensen FB, Holm R, Bunger CE, Oestergaard LG. Does a preoperative cognitive-behavioral intervention affect disability, pain behavior, pain, and return to work the first year after lumbar spinal fusion surgery? Spine. 2015;40(9):593-600.

70. Louw A, Diener I, Landers MR, Zimney K, Puentedura EJ. Three-year follow-up of a randomized controlled trial comparing preoperative neuroscience education for patients undergoing surgery for lumbar radiculopathy. Journal of spine surgery (Hong Kong). 2016;2(4):289-98.

71. Moseley GL, Nicholas MK, Hodges PW. A randomized controlled trial of intensive neurophysiology education in chronic low back pain. The Clinical journal of pain. 2004;20(5):324-30.

72. Brox JI, Storheim K, Grotle M, Tveito TH, Indahl A, Eriksen HR. Evidence-informed management of chronic low back pain with back schools, brief education, and fear-avoidance training. The spine journal : official journal of the North American Spine Society. 2008;8(1):28-39.

73. Burns JW, Nielson WR, Jensen MP, Heapy A, Czlapinski R, Kerns RD. Specific and general therapeutic mechanisms in cognitive behavioral treatment of chronic pain. Journal of consulting and clinical psychology. 2015;83(1):1-11.

74. Schmid J, Bingel U, Ritter C, Benson S, Schedlowski M, Gramsch C, et al. Neural underpinnings of nocebo hyperalgesia in visceral pain: A fMRI study in healthy volunteers. NeuroImage. 2015;120:114-22.

75. Kehlet H, Wilmore DW. Multimodal strategies to improve surgical outcome. American journal of surgery. 2002;183(6):630-41.

76. Kraemer WJ, Adams K, Cafarelli E, Dudley GA, Dooly C, Feigenbaum MS, et al. American College of Sports Medicine position stand. Progression models in resistance training for healthy adults. Medicine and science in sports and exercise. 2002;34(2):364-80. 
77. Howley ET. Type of activity: resistance, aerobic and leisure versus occupational physical activity. Medicine and science in sports and exercise. 2001;33(6 Suppl):S364-9; discussion S419-20.

78. Naugle KM, Fillingim RB, Riley JL, 3rd. A meta-analytic review of the hypoalgesic effects of exercise. The journal of pain : official journal of the American Pain Society. 2012;13(12):1139-50.

79. Naugle KM, Naugle KE, Fillingim RB, Samuels B, Riley JL, 3rd. Intensity thresholds for aerobic exercise-induced hypoalgesia. Medicine and science in sports and exercise. 2014;46(4):817-25.

80. Koltyn KF, Umeda M. Exercise, hypoalgesia and blood pressure. Sports medicine (Auckland, NZ). 2006;36(3):207-14.

81. Dietrich A, McDaniel WF. Endocannabinoids and exercise. British journal of sports medicine. 2004;38(5):536-41.

82. Knapen J, Vancampfort D, Morien Y, Marchal Y. Exercise therapy improves both mental and physical health in patients with major depression. Disability and rehabilitation. 2015;37(16):1490-5.

83. Borg GA. Psychophysical bases of perceived exertion. Med Sci Sports Exerc. 1982;14(5):377-81.

84. Meyer JD, Koltyn KF, Stegner AJ, Kim JS, Cook DB. Influence of Exercise Intensity for Improving Depressed Mood in Depression: A Dose-Response Study. Behavior therapy. 2016;47(4):527-37.

85. Lampinen P, Heikkinen RL, Ruoppila I. Changes in intensity of physical exercise as predictors of depressive symptoms among older adults: an eightyear follow-up. Preventive medicine. 2000;30(5):371-80.

86. Airaksinen O, Brox JI, Cedraschi C, Hildebrandt J, Klaber-Moffett J, Kovacs F, et al. Chapter 4. European guidelines for the management of chronic nonspecific low back pain. European spine journal : official publication of the European Spine Society, the European Spinal Deformity Society, and the European Section of the Cervical Spine Research Society. 2006;15 Suppl 2:S192-300.

87. Chapman JR, Norvell DC, Hermsmeyer JT, Bransford RJ, DeVine J, McGirt MJ, et al. Evaluating common outcomes for measuring treatment success for chronic low back pain. Spine. 2011;36(21 Suppl):S54-68.

88. Cruz-Almeida Y, Fillingim RB. Can quantitative sensory testing move us closer to mechanism-based pain management? Pain medicine (Malden, Mass). 2014;15(1):61-72.

89. Rolke R, Magerl W, Campbell KA, Schalber C, Caspari S, Birklein F, et al. Quantitative sensory testing: a comprehensive protocol for clinical trials. Eur J Pain. 2006;10(1):77-88.

90. Cruccu G, Anand P, Attal N, Garcia-Larrea L, Haanpaa M, Jorum E, et al. EFNS guidelines on neuropathic pain assessment. European journal of neurology. 2004;11(3):153-62.

91. Marcuzzi A, Dean CM, Wrigley PJ, Chakiath RJ, Hush JM. Prognostic value of quantitative sensory testing in low back pain: a systematic review of the literature. Journal of pain research. 2016;9:599-607. 
92. Blumenstiel K, Gerhardt A, Rolke R, Bieber C, Tesarz J, Friederich HC, et al. Quantitative sensory testing profiles in chronic back pain are distinct from those in fibromyalgia. The Clinical journal of pain. 2011;27(8):68290.

93. Patton MQ. Qualitative Research \& Evaluation Methods. 4 ed: Thousand Oaks, CA, USA, Sage; 2014.

94. Dicicco-Bloom B, Crabtree BF. The qualitative research interview. Medical education. 2006;40(4):314-21.

95. Costigan M, Scholz J, Woolf CJ. Neuropathic pain: a maladaptive response of the nervous system to damage. Annual review of neuroscience. 2009;32:1-32.

96. Lindback Y, Tropp H, Enthoven P, Abbott A, Oberg B. PREPARE: Presurgery physiotherapy for patients with degenerative lumbar spine disorder: a randomized controlled trial protocol. BMC musculoskeletal disorders. 2016;17:270.

97. Fairbank JC, Couper J, Davies JB, O'Brien JP. The Oswestry low back pain disability questionnaire. Physiotherapy. 1980;66(8):271-3.

98. Dworkin RH, Turk DC, Farrar JT, Haythornthwaite JA, Jensen MP, Katz NP, et al. Core outcome measures for chronic pain clinical trials: IMMPACT recommendations. Pain. 2005;113(1-2):9-19.

99. The National Board of health and welfare (Socialstyrelsen) Public health report 2001 (Folkhälosrapport 2001) [2018-08-12]. Page 251-2]. Available from: https://docplayer.se/3131541-Folkhalsorapport-2001.html.

100. Borsbo B, Liedberg GM, Wallin M, Gerdle B. Subgroups based on thermal and pressure pain thresholds in women with chronic whiplash display differences in clinical presentation - an explorative study. Journal of pain research. 2012;5:511-21.

101. Wallin M, Liedberg G, Borsbo B, Gerdle B. Thermal detection and pain thresholds but not pressure pain thresholds are correlated with psychological factors in women with chronic whiplash-associated pain. The Clinical journal of pain. 2012;28(3):211-21.

102. Scott J, Huskisson EC. Graphic representation of pain. Pain. 1976;2(2):17584.

103. Heldestad V, Linder J, Sellersjo L, Nordh E. Reproducibility and influence of test modality order on thermal perception and thermal pain thresholds in quantitative sensory testing. Clinical neurophysiology: official journal of the International Federation of Clinical Neurophysiology. 2010;121(11):1878-85.

104. Marcuzzi A, Wrigley PJ, Dean CM, Adams R, Hush JM. The long-term reliability of static and dynamic quantitative sensory testing in healthy individuals. Pain. 2017;158(7):1217-23.

105. Zwart JA, Sand T. Repeatability of dermatomal warm and cold sensory thresholds in patients with sciatica. European spine journal : official publication of the European Spine Society, the European Spinal Deformity Society, and the European Section of the Cervical Spine Research Society. 2002;11(5):441-6. 
106. Kinser AM, Sands WA, Stone MH. Reliability and validity of a pressure algometer. Journal of strength and conditioning research. 2009;23(1):312-4.

107. Balaguier R, Madeleine P, Vuillerme N. Is One Trial Sufficient to Obtain Excellent Pressure Pain Threshold Reliability in the Low Back of Asymptomatic Individuals? A Test-Retest Study. PloS one. 2016;11(8):e0160866.

108. Southerst D, Cote P, Stupar M, Stern P, Mior S. The reliability of body pain diagrams in the quantitative measurement of pain distribution and location in patients with musculoskeletal pain: a systematic review. Journal of manipulative and physiological therapeutics. 2013;36(7):450-9.

109. Zigmond AS, Snaith RP. The hospital anxiety and depression scale. Acta psychiatrica Scandinavica. 1983;67(6):361-70.

110. Altmaier E. Role of self-efficacy in rehabilitation outcome among chronic low back pain patients. Journal of Counseling Psychology. 1993;40(3):3359.

111. Waddell G, Newton M, Henderson I, Somerville D, Main CJ. A FearAvoidance Beliefs Questionnaire (FABQ) and the role of fear-avoidance beliefs in chronic low back pain and disability. Pain. 1993;52(2):157-68.

112. Cleland JA, Whitman JM, Houser JL, Wainner RS, Childs JD.

Psychometric properties of selected tests in patients with lumbar spinal stenosis. The spine journal : official journal of the North American Spine Society. 2012;12(10):921-31.

113. DeVine J, Norvell DC, Ecker E, Fourney DR, Vaccaro A, Wang J, et al. Evaluating the correlation and responsiveness of patient-reported pain with function and quality-of-life outcomes after spine surgery. Spine. 2011;36(21 Suppl):S69-74.

114. Brooks R. EuroQol: the current state of play. Health policy (Amsterdam, Netherlands). 1996;37(1):53-72.

115. EuroQolGroup. EuroQol--a new facility for the measurement of healthrelated quality of life. Health Policy. 1990;16(3):199-208.

116. Aaronson NK, Acquadro C, Alonso J, Apolone G, Bucquet D, Bullinger M, et al. International Quality of Life Assessment (IQOLA) Project. Qual Life Res. 1992;1(5):349-51.

117. Burstrom K, Johannesson M, Diderichsen F. Swedish population healthrelated quality of life results using the EQ-5D. Qual Life Res. 2001;10(7):621-35.

118. Persson LO, Karlsson J, Bengtsson C, Steen B, Sullivan M. The Swedish SF-36 Health Survey II. Evaluation of clinical validity: results from population studies of elderly and women in Gothenborg. Journal of clinical epidemiology. 1998;51(11):1095-103.

119. Sullivan M, Karlsson J, Ware JE, Jr. The Swedish SF-36 Health Survey--I. Evaluation of data quality, scaling assumptions, reliability and construct validity across general populations in Sweden. Social science \& medicine (1982). 1995;41(10):1349-58. 
120. Sullivan M, Karlsson J. The Swedish SF-36 Health Survey III. Evaluation of criterion-based validity: results from normative population. Journal of clinical epidemiology. 1998;51(11):1105-13.

121. Soderlund A, Olerud C, Lindberg P. Acute whiplash-associated disorders (WAD): the effects of early mobilization and prognostic factors in longterm symptomatology. Clinical rehabilitation. 2000;14(5):457-67.

122. Bjelland I, Dahl AA, Haug TT, Neckelmann D. The validity of the Hospital Anxiety and Depression Scale. An updated literature review. J Psychosom Res. 2002;52(2):69-77.

123. Denison E, Asenlof P, Lindberg P. Self-efficacy, fear avoidance, and pain intensity as predictors of disability in subacute and chronic musculoskeletal pain patients in primary health care. Pain. 2004;111(3):245-52.

124. Bunketorp L, Carlsson J, Kowalski J, Stener-Victorin E. Evaluating the reliability of multi-item scales: a non-parametric approach to the ordered categorical structure of data collected with the Swedish version of the Tampa Scale for Kinesiophobia and the Self-Efficacy Scale. Journal of rehabilitation medicine. 2005;37(5):330-4.

125. Stanton TR, Fritz JM, Hancock MJ, Latimer J, Maher CG, Wand BM, et al. Evaluation of a treatment-based classification algorithm for low back pain: a cross-sectional study. Physical therapy. 2011;91(4):496-509.

126. Stratford PG, C.; Westaway, M.;Brinkley, J. . Assessing disability and change on individual patients: a report of a patient specific measure. Physiotherapy Can. 1995;47:258-63.

127. Rainville J, Smeets RJ, Bendix T, Tveito TH, Poiraudeau S, Indahl AJ. Fear-avoidance beliefs and pain avoidance in low back pain--translating research into clinical practice. The spine journal : official journal of the North American Spine Society. 2011;11(9):895-903.

128. Magerl W, Krumova EK, Baron R, Tolle T, Treede RD, Maier C. Reference data for quantitative sensory testing (QST): refined stratification for age and a novel method for statistical comparison of group data. Pain. 2010;151(3):598-605.

129. Pfau DB, Krumova EK, Treede RD, Baron R, Toelle T, Birklein F, et al. Quantitative sensory testing in the German Research Network on Neuropathic Pain (DFNS): reference data for the trunk and application in patients with chronic postherpetic neuralgia. Pain. 2014;155(5):1002-15.

130. Hagg O, Fritzell P, Nordwall A. The clinical importance of changes in outcome scores after treatment for chronic low back pain. European spine journal : official publication of the European Spine Society, the European Spinal Deformity Society, and the European Section of the Cervical Spine Research Society. 2003;12(1):12-20.

131. Cohen J. A power primer. Psychological bulletin. 1992;112(1):155-9.

132. Azur MJ, Stuart EA, Frangakis C, Leaf PJ. Multiple imputation by chained equations: what is it and how does it work? International journal of methods in psychiatric research. 2011;20(1):40-9.

133. de Vet HC, Ostelo RW, Terwee CB, van der Roer N, Knol DL, Beckerman $\mathrm{H}$, et al. Minimally important change determined by a visual method 
integrating an anchor-based and a distribution-based approach. Qual Life Res. 2007;16(1):131-42.

134. Soer R, Reneman MF, Vroomen PC, Stegeman P, Coppes MH.

Responsiveness and minimal clinically important change of the Pain

Disability Index in patients with chronic back pain. Spine. 2012;37(8):7115.

135. Hsieh HF, Shannon SE. Three approaches to qualitative content analysis. Qualitative health research. 2005;15(9):1277-88.

136. Smart KM, Blake C, Staines A, Thacker M, Doody C. Mechanisms-based classifications of musculoskeletal pain: part 2 of 3: symptoms and signs of peripheral neuropathic pain in patients with low back (+/- leg) pain. Manual therapy. 2012;17(4):345-51.

137. Wylde V, Sayers A, Lenguerrand E, Gooberman-Hill R, Pyke M, Beswick AD, et al. Preoperative widespread pain sensitization and chronic pain after hip and knee replacement: a cohort analysis. Pain. 2015;156(1):47-54.

138. Puta C, Schulz B, Schoeler S, Magerl W, Gabriel B, Gabriel HH, et al. Somatosensory abnormalities for painful and innocuous stimuli at the back and at a site distinct from the region of pain in chronic back pain patients. PloS one. 2013;8(3):e58885.

139. Freynhagen R, Baron R. The evaluation of neuropathic components in low back pain. Current pain and headache reports. 2009;13(3):185-90.

140. Reddi D. Preventing chronic postoperative pain. Anaesthesia. 2016;71 Suppl 1:64-71.

141. Smart KM, Blake C, Staines A, Doody C. The Discriminative validity of "nociceptive," "peripheral neuropathic," and "central sensitization" as mechanisms-based classifications of musculoskeletal pain. The Clinical journal of pain. 2011;27(8):655-63.

142. Neblett R, Hartzell MM, Mayer TG, Cohen H, Gatchel RJ. Establishing Clinically Relevant Severity Levels for the Central Sensitization Inventory. Pain practice : the official journal of World Institute of Pain. 2017;17(2):166-75.

143. van der Roer N, Ostelo RW, Bekkering GE, van Tulder MW, de Vet HC. Minimal clinically important change for pain intensity, functional status, and general health status in patients with nonspecific low back pain. Spine. 2006;31(5):578-82.

144. Solberg T, Johnsen LG, Nygaard OP, Grotle M. Can we define success criteria for lumbar disc surgery? : estimates for a substantial amount of improvement in core outcome measures. Acta orthopaedica. 2013;84(2):196-201.

145. Adogwa O, Carr K, Fatemi P, Verla T, Gazcon G, Gottfried O, et al. Psychosocial factors and surgical outcomes: are elderly depressed patients less satisfied with surgery? Spine. 2014;39(19):1614-9.

146. Sinikallio S, Lehto SM, Aalto T, Airaksinen O, Kroger H, Viinamaki H. Depressive symptoms during rehabilitation period predict poor outcome of lumbar spinal stenosis surgery: a two-year perspective. BMC musculoskeletal disorders. 2010;11:152. 
147. Havakeshian S, Mannion AF. Negative beliefs and psychological disturbance in spine surgery patients: a cause or consequence of a poor treatment outcome? European spine journal : official publication of the European Spine Society, the European Spinal Deformity Society, and the European Section of the Cervical Spine Research Society. 2013;22(12):2827-35.

148. Grotle M, Vollestad NK, Brox JI. Clinical course and impact of fearavoidance beliefs in low back pain: prospective cohort study of acute and chronic low back pain: II. Spine. 2006;31(9):1038-46.

149. Burgstaller JM, Wertli MM, Steurer J, Kessels AG, Held U, Gramke HF. The Influence of Pre- and Postoperative Fear Avoidance Beliefs on Postoperative Pain and Disability in Patients With Lumbar Spinal Stenosis: Analysis of the Lumbar Spinal Outcome Study (LSOS) Data. Spine. 2017;42(7):E425-e32.

150. Brox JI, Sorensen R, Friis A, Nygaard O, Indahl A, Keller A, et al. Randomized clinical trial of lumbar instrumented fusion and cognitive intervention and exercises in patients with chronic low back pain and disc degeneration. Spine. 2003;28(17):1913-21.

151. Svensson GL, Wendt GK, Thomee R. A structured physiotherapy treatment model can provide rapid relief to patients who qualify for lumbar disc surgery: a prospective cohort study. Journal of rehabilitation medicine. 2014;46(3):233-40.

152. Schmidt CT, Ward RE, Suri P, Kiely DK, Goldstein R, Pensheng N, et al. Which Neuromuscular Attributes Are Associated With Changes in Mobility Among Community-Dwelling Older Adults With Symptomatic Lumbar Spinal Stenosis? Archives of physical medicine and rehabilitation. 2018.

153. Fernandes L, Hagen KB, Bijlsma JW, Andreassen O, Christensen P, Conaghan PG, et al. EULAR recommendations for the nonpharmacological core management of hip and knee osteoarthritis. Annals of the rheumatic diseases. 2013;72(7):1125-35.

154. Cuff A, Littlewood C. Subacromial impingement syndrome - What does this mean to and for the patient? A qualitative study. Musculoskeletal science \& practice. 2018;33:24-8.

155. Louw A, Zimney K, Puentedura EJ, Diener I. The efficacy of pain neuroscience education on musculoskeletal pain: A systematic review of the literature. Physiotherapy theory and practice. 2016;32(5):332-55.

156. Deyo RA, Martin BI, Kreuter W, Jarvik JG, Angier H, Mirza SK. Revision surgery following operations for lumbar stenosis. The Journal of bone and joint surgery American volume. 2011;93(21):1979-86.

157. Zaina F, Tomkins-Lane C, Carragee E, Negrini S. Surgical Versus Nonsurgical Treatment for Lumbar Spinal Stenosis. Spine. 2016;41(14):E857-68.

158. Limback Svensson G, Kjellby Wendt G, Thomee R, Danielson E. Patients' experience of health three years after structured physiotherapy or surgery for lumbar disc herniation. Journal of rehabilitation medicine. 2013;45(3):293-9. 
159. Lynch AD, Bove AM, Ammendolia C, Schneider M. Individuals with lumbar spinal stenosis seek education and care focused on self-management - results of focus groups among participants enrolled in a randomized controlled trial. The spine journal : official journal of the North American Spine Society. 2017.

160. Suokas AK, Walsh DA, McWilliams DF, Condon L, Moreton B, Wylde V, et al. Quantitative sensory testing in painful osteoarthritis: a systematic review and meta-analysis. Osteoarthritis and cartilage. 2012;20(10):107585.

161. Neziri AY, Curatolo M, Limacher A, Nuesch E, Radanov B, Andersen OK, et al. Ranking of parameters of pain hypersensitivity according to their discriminative ability in chronic low back pain. Pain. 2012;153(10):208391.

162. Goldsmith R, Wright C, Bell SF, Rushton A. Cold hyperalgesia as a prognostic factor in whiplash associated disorders: a systematic review. Manual therapy. 2012;17(5):402-10. 


\section{Papers}

The papers associated with this thesis have been removed for copyright reasons. For more details about these see:

http://urn.kb.se/resolve?urn=urn:nbn:se:liu:diva-150553 